\title{
Fast cloud parameter retrievals of MIPAS/Envisat
}

\author{
R. Spang ${ }^{1}$, K. Arndt ${ }^{1, *}$, A. Dudhia ${ }^{2}$, M. Höpfner ${ }^{4}$, L. Hoffmann ${ }^{1,7}$, J. Hurley ${ }^{2}$, R. G. Grainger ${ }^{2}$, S. Griessbach ${ }^{1,7}$, \\ C. Poulsen ${ }^{3}$, J. J. Remedios ${ }^{5}$, M. Riese ${ }^{1}$, H. Sembhi ${ }^{5}$, R. Siddans ${ }^{3}$, A. Waterfall ${ }^{3}$, and C. Zehner ${ }^{6}$ \\ ${ }^{1}$ Forschungszentrum Jülich, Institut für Energie and Klimaforschung, IEK-7, Jülich, Germany \\ ${ }^{2}$ University of Oxford, AOPP, Oxford, UK \\ ${ }^{3}$ Rutherford Appleton Laboratory, Chilton, Didcot, UK \\ ${ }^{4}$ Karlsruhe Institute of Technology, IMK, Karlsruhe, Germany \\ ${ }^{5}$ University of Leicester, EOS, Leicester, UK \\ ${ }^{6}$ ESA-ESRIN, Frascati, Italy \\ ${ }^{7}$ Forschungszentrum Jülich, Jülich Supercomputing Centre, JSC, Jülich, Germany \\ *now at: Thinking Network AG, Aachen, Germany
}

Correspondence to: R. Spang (r.spang@fz-juelich.de)

Received: 6 June 2011 - Published in Atmos. Chem. Phys. Discuss.: 14 December 2011

Revised: 5 June 2012 - Accepted: 5 July 2012 - Published: 7 August 2012

\begin{abstract}
The infrared limb spectra of the Michelson Interferometer for Passive Atmospheric Sounding (MIPAS) on board the Envisat satellite include detailed information on tropospheric clouds and polar stratospheric clouds (PSC). However, no consolidated cloud product is available for the scientific community. Here we describe a fast prototype processor for cloud parameter retrieval from MIPAS (MIPclouds). Retrieval of parameters such as cloud top height, temperature, and extinction are implemented, as well as retrieval of microphysical parameters, e.g. effective radius and the integrated quantities over the limb path (surface area density and volume density). MIPclouds classifies clouds as either liquid or ice cloud in the upper troposphere and polar stratospheric clouds types in the stratosphere based on statistical combinations of colour ratios and brightness temperature differences.

Comparison of limb measurements of clouds with model results or cloud parameters from nadir looking instruments is often difficult due to different observation geometries. We therefore introduce a new concept, the limb-integrated surface area density path (ADP). By means of validation and radiative transfer calculations of realistic 2-D cloud fields as input for a blind test retrieval (BTR), we demonstrate that ADP is an extremely valuable parameter for future comparison with model data of ice water content, when applying limb integration (ray tracing) through the model fields. In addition, ADP is used for a more objective definition of detec-
\end{abstract}

tion thresholds of the applied detection methods. Based on BTR, a detection threshold of ADP $=10^{7} \mu \mathrm{m}^{2} \mathrm{~cm}^{-2}$ and an ice water content of $10^{-5} \mathrm{~g} \mathrm{~m}^{-3}$ is estimated, depending on the horizontal and vertical extent of the cloud.

Intensive validation of the cloud detection methods shows that the limb-sounding MIPAS instrument has a sensitivity in detecting stratospheric and tropospheric clouds similar to that of space- and ground-based lidars, with a tendency for higher cloud top heights and consequently higher sensitivity for some of the MIPAS detection methods. For the high cloud amount (HCA, pressure levels below $440 \mathrm{hPa}$ ) on global scales the sensitivity of MIPAS is significantly greater than that of passive nadir viewers. This means that the high cloud fraction will be underestimated in the ISCCP dataset compared to the amount of high clouds deduced by MIPAS. Good correspondence in seasonal variability and geographical distribution of cloud occurrence and zonal means of cloud top height is found in a detailed comparison with a climatology for subvisible cirrus clouds from the Stratospheric Aerosol and Gas Experiment II (SAGE II) limb sounder. Overall, validation with various sensors shows the need to consider differences in sensitivity, and especially the viewing geometries and field-of-view size, to make the datasets comparable (e.g. applying integration along the limb path through nadir cloud fields). The simulation of the limb path integration will be an important issue for comparisons with cloud-resolving global circulation or chemical transport models. 


\section{Introduction}

The Michelson Interferometer for Passive Atmospheric Sounding (MIPAS) on board the ENVISAT satellite measures limb infrared (IR) spectra in the wavelength range from 4 to $15 \mu \mathrm{m}$ (Fischer et al., 2008). The MIPAS radiance spectra contain a variety of crucial data on atmospheric processes including cloud formation and chemical interaction of clouds and trace gases. The exploration of cloud spectra - measured globally with very high spectral resolution in the limb - has been investigated in more detail in the last $10 \mathrm{yr}$. First publications already demonstrate the great scientific impact these data can achieve (Spang et al., 2005a, b; Ewen et al., 2005; Höpfner et al., 2006a). For example, IR limb measurements from space are extremely sensitive to the detection of optically thin clouds in the upper troposphere and lower stratosphere (UTLS) (Mergenthaler et al., 1999; Spang et al., 2002; Massie et al., 2007), such as subvisible cirrus (SVC) (Sassen et al., 1989) or ultrathin tropical cirrus (Peter et al., 2003; Luo et al., 2003). A large proportion of the uncertainties of climate change prediction using general circulation models (GCMs) arises from poorly understood and represented interactions and feedbacks between dynamic, microphysical, and radiative processes affecting cirrus clouds. Modelled climates are sensitive even to small changes in cirrus coverage or ice microphysics (Kärcher and Spichtinger, 2010). Optically thin cirrus in the tropical tropopause layer dehydrates the air entering the stratosphere, thus affecting stratospheric water vapour and ozone concentrations (Zhang et al., 2005). All these processes highlight the importance of quantitative information on clouds and especially optically thin cirrus clouds, where MIPAS can provide a substantial amount of information.

MIPAS is the first instrument which allows the compilation of a pole-covering climatology on the occurrence of polar stratospheric clouds (PSC) and the classification of various cloud types under daytime and night-time conditions (Spang et al., 2005a, b; Höpfner et al., 2006b). The PSC measurements are valuable for validating the treatment of polar chemistry by climate chemistry models (CCMs) and thus providing confidence in the prediction of future polar ozone loss. CCMs used for assessments of stratospheric ozone loss (e.g. Eyring, et al., 2005) often employ rather simple heterogeneous chemistry schemes. The simpler schemes are frequently based on nitric acid trihydrate (NAT), although it is known that heterogeneous chemistry on supercooled ternary solution (STS) and on cold binary aerosol particles probably dominates polar chlorine activations (e.g. Solomon, 1999; Drdla and Müller, 2010). The activation potential and temperature formation threshold of different types of PSC are very different. Therefore, detailed information about observed PSC compositions is a prerequisite for an accurate, process-based simulation of chlorine activation in polar ozone chemistry and the prediction of the recovery of the Antarctic ozone hole.
Raspolini et al. (2002) showed that cloud spectra may have a significant impact on the retrieval of pressure, temperature and trace gas profiles and proper cloud screening is necessary to avoid erroneous retrieval results. The ESA operational MIPAS level 1 and 2 products do not include any information on clouds and aerosols. This is not surprising, because the analysis and retrieval of cloud parameter from limb IR spectra is a challenging and time-consuming task due to the complex radiative transfer in the presence of clouds.

A validated and consolidated MIPAS cloud product is currently not available for the scientific community and the development of a cloud processor providing standardised and validated cloud product parameters would be extremely valuable. Consequently, MIPclouds, a prototype of a cloud parameter processor, was developed as part of an ESA-funded study with the emphasis on time-efficient processing - with a speed faster than near-real-time (NRT) - where simple techniques such as colour ratios or simplified radiative transfer models are applied to match the NRT constraint.

To date, the focus of most scientific analysis of MIPAS cloud observations is on the analysis of PSC (Spang et al., 2005a, Höpfner et al., 2006a, b, 2009) or technical aspects of the cloud parameter retrieval (Spang et al., 2005; Greenhough et al., 2005; Hurley et al., 2009, 2011; Sembhi et al., 2012). For the first time this paper presents a combination of the best suited detection methods and new developed cloud parameter retrievals in one processing system with corresponding data products. A stringent cross-validation of the applied detection methods with cloud products of other satellite instruments is performed to optimise, quantify, and validate the detection sensitivity of the new, combined approach. First attempts for a more adequate comparison of cloud products of different instrument types and viewing geometries are presented and applied to the data. Finally, this paper introduces to the scientific community a new and - after the completion of the processing of the full measurement period - a $10 \mathrm{yr}$ data record of cloud products for future comparisons with model data (e.g. GCM or ECMWF re-analyses) or with combined cloud datasets of operational nadir instruments.

This article is organised as follows. First, Sect. 2 will give an overview of the MIPclouds processing system, followed by Sect. 3 with a description of the algorithms and techniques applied in the processing. Section 4 will introduce a blind test retrieval approach used for validation and consolidation of retrieval parameters. Finally, validation results are presented and discussed with the focus on cloud detection and cloud occurrence. In the following sections all algorithm and validation results are based on the software version 1.6 of the processor.

\section{Overall structure of the processor}

The simple flow chart in Fig. 1 illustrates the workflow of the data processing. In a first step, various data sources such 


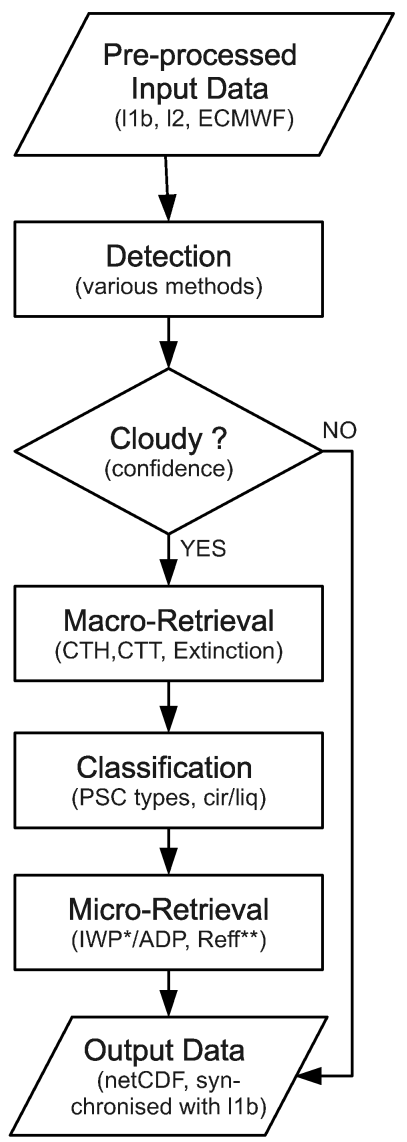

Fig. 1. Overview of the MIPclouds processing scheme. The preprocessing of the input data is part of the original cloud processor. (*) Ice water path (IWP) is an integrated quantity over the limb path, as well as for the area density path (ADP). $\left({ }^{* *}\right)$ For the current processor version, retrieval results of $R_{\mathrm{eff}}$ are not recommended for scientific analyses, further investigations and improvements on the algorithms are necessary.

as the level $1 \mathrm{~b}$ (L1b), level 2 (L2), and reanalysis data from the European Centre for Medium-Range Weather Forecasts (ECMWF) are merged on basis of the spatial collocation of calibrated L1b spectra. Pre-processing creates a consolidated profile-based dataset of radiances for a number of specified microwindows. This step includes an altitude correction of uncertainties up to two kilometres of the original level $1 \mathrm{~b}$ engineering heights (Kiefer et al., 2007) and the Norton-Beer apodisation of the spectra. The final corrected tangent altitude is assumed to be accurate in the order of $200 \mathrm{~m}, 500 \mathrm{~m}$ and $\pm 1.5 \mathrm{~km}$ depending on the level of correction that can be achieved (e.g. von Clarmann et al. 2003, details on the altitude correction of the processor are given in the Supplement). Various cloud detection methods are then applied and combined for the most relevant decision of the processing, if a spectrum has to be flagged as cloudy or non-cloudy. After this step, the retrieval of macroscopic cloud properties (cloud top height, temperature and extinction, abbreviated below with macro retrieval) starts. Subsequently, a cloud classification takes place based on the top two cloudy tangent heights. In the free troposphere $(>5 \mathrm{~km})$ and UTLS region, cloudy spectra are classified as belonging to either water or and cirrus clouds. In the polar winter stratosphere cloudy radiances are classified as originating from ice, nitric acid trihydrate, or liquid supercooled ternary solutions droplets. Based on the classification, additional microphysical parameters are estimated such as the effective radius $\left(R_{\text {eff }}\right)$, the limb integrated volume or surface area density path (VDP and ADP), along with some simplified estimates of volume density and ice water content.

For validation purposes, such as comparisons with other sensor and cloud climatologies, it is essential to compute cloud occurrence frequencies (COF) based on the retrieved cloud top height. The $\mathrm{COF}$ is an important secondary product of the processor. However, as we show in Sect. 5, a correct comparison of COF needs specific refinements depending on the measurement characteristics of each sensor, such as observation geometry or the size of the field of view.

The MIPAS instrument made nearly continuous measurements from September 2002 to March 2004 in the full resolution mode of the spectrometer $\left(0.025 \mathrm{~cm}^{-1}\right.$ spectral sampling). These measurements were taken as the primary dataset of interest for the application of the new prototype processor and the following analyses and validation results are restricted to this time period. However, special care was also taken to keep the algorithms flexible so that only minor modifications would be necessary to allow processing of measurements in the so-called optimised resolution mode $\left(0.0625 \mathrm{~cm}^{-1}\right)$ for data from 2005 onward.

\section{Algorithms and techniques}

This section summarises the algorithms applied for the retrieval of cloud parameters in the processing system. Some methods have already been published or recently submitted to peer-reviewed journals (specific references see sections below). Consequently these methods are described here only briefly. In addition, a more technical description of all the algorithms is given in Spang et al. (2010a). For better orientation of the readers, a number of frequently used acronyms and shortcuts in the manuscript are listed in Appendix A.

\subsection{Cloud detection}

A number of complementary cloud detection methods are implemented as initial steps in the processing scheme: (a) the multi-colour ratio (Cloud Index: $\mathrm{CI}$ ) approach in various wavelength regions with improved threshold definition, (b) a singular value decomposition (SVD) approach for cloud detection, (c) a multi wavelength (10) microwindows method at $930-960 \mathrm{~cm}^{-1}$, and finally (d) a weighted combination of 


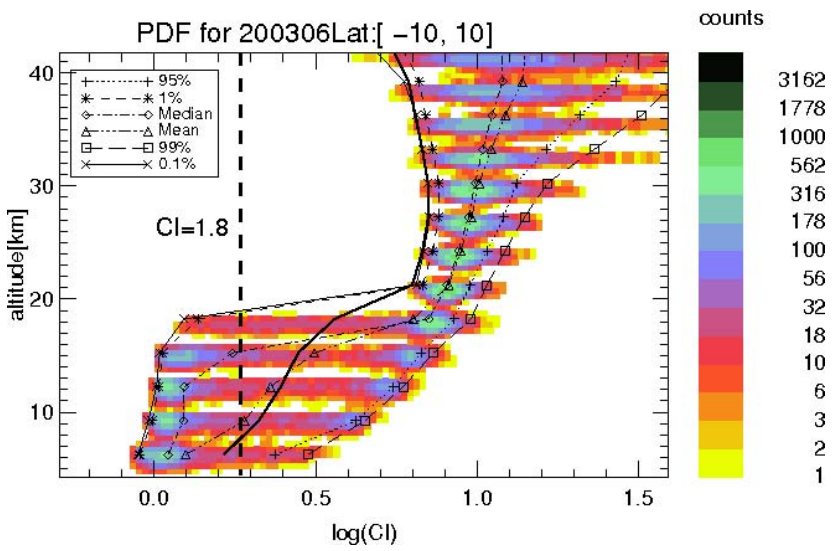

Fig. 2. The probability density distribution of $\log _{10}\left(C I_{\mathrm{A}}\right)$ for MIPAS measurements in June 2003 in the equator region $( \pm 10 \mathrm{deg}$ latitude). Superimposed on a $3 \mathrm{~km}$ vertical grid various percentiles (0.1, 1, 50 (median), 95, and 99\%), a mean, and an optimised CI threshold profile (thick solid vertical line, details see text) as well as the constant threshold of $\mathrm{CI}=1.8$ (thick dashed line). Horizontal stripes are caused by the accurate pointing of the nominal tangent height ( $3 \mathrm{~km}$ altitude grid with minimum heights around $6-7 \mathrm{~km}$ ).

the cloud detection flag of each method for the determination of detection confidence.

\subsubsection{Colour-ratio-based methods}

For the ESA L2 processing, a fast and effective cloud detection method is required to identify cloud-contaminated MIPAS spectra. Historically, this function has been fulfilled by the cloud index (CI) method based on the approach originally described in Spang et al. (2002) for the CRyogenic Infrared Spectrometers and Telescopes for the Atmosphere (CRISTA) data processing (Riese et al., 1997, 1999) and extended to MIPAS in Spang et al. (2004). Although its original purpose was to remove cloudy spectra from trace gas retrievals, the CI method was also used successfully to derive cloud distributions and occurrence frequencies from MIPAS (e.g. Greenhough et al., 2005; Spang et al., 2005b).

\section{The standard operational CI approach (OPER_CI)}

The CI method is based on the simple relation for a colour ratio of mean radiances in different spectral regions:

$$
\mathrm{CI}=\frac{\frac{1}{n_{1}} \sum_{i=1}^{n_{1}} L_{i}\left(v_{i 1}\right)}{\frac{1}{n_{2}} \sum_{i=1}^{n_{2}} L_{i}\left(v_{i 2}\right)},
$$

with $L_{i}$ being the radiance measured at the wavenumber $v_{i}$ with indices 1 and 2 of the corresponding microwindow (MW) pair. Typically $\mathrm{MW}_{1}$ represents a region where a strong trace gas emitter is present, for example $\mathrm{CO}_{2}$, and $\mathrm{MW}_{2}$ is typically part of an atmospheric window region.

Table 1 shows the selected wavenumber regions and CI thresholds for the processing. The main intention of the new processor was to enhance detection sensitivity by introducing CI threshold profiles dependent on latitude, altitude and time, which consider the clear sky variability of radiance in the selected MWs, instead of the robust but simple constant thresholds used in various MIPAS retrieval processors (e.g. Raspollini et al., 2002, 2006; Milz et al., 2005; Hoffmann et al., 2008), where the variability in the thresholds (e.g. $\mathrm{CI}_{\mathrm{A}}$ thresholds vary from 1.8 to 4.5 ) is based on criteria of how much cloud emission will still allow accurate trace gas retrievals.

\section{A variable CI threshold profile based on MIPAS 2003 observationsm (CI_THRESH)}

An example of the number density distribution for the selected colour ratio in MIPAS band $\mathrm{A}\left(\mathrm{CI}_{\mathrm{A}}\right)$ is presented in Fig. 2. Typically, values for $\mathrm{CI}_{\mathrm{A}}$ are close to unity when an optically thick cloud is present in the MIPAS field of view $(\mathrm{FOV})$ and $\mathrm{CI}_{\mathrm{A}}$ tends to be large $\left(\mathrm{CI}_{\mathrm{A}}>6.0\right)$ for a clear sky conditons. Low to high $\mathrm{CI}_{\mathrm{A}}$ values represents the transition from optically thick to optically thin clouds. A bimodal character of the lower altitude CI values is obvious for tropospheric measurements (below $\sim 18 \mathrm{~km}$ in the tropics) and is also observed in the polar winter stratosphere caused by PSC occurrences (not shown). The transition region between the two maxima is created by optically thin clouds or by clouds filling only part of FOV of the instrument. However, in the free troposphere enhanced continuum emission of water vapour can also significantly reduce the CI value, which can be artificially interpreted as an effect by clouds. This is typically a problem for water mixing ratios $>500$ 1000 ppmv (Spang et al., 2004).

In a first step, new threshold profiles for $\mathrm{CI}_{\mathrm{A}}$ were defined using a 1-yr climatology (2003) of MIPAS $\mathrm{CI}_{\mathrm{A}}$ values. The threshold profile is a combination of the 1st percentile plus a tolerance for altitudes above the level where the bimodal character becomes obvious. This is usually around the tropopause (Fig. 2) or during the PSC season in the stratosphere at altitudes up to $26 \mathrm{~km}$. Below this level in the area of the bimodal distribution a threshold is defined by the centre of the 99th and 1st percentile in the $\log _{10}(\mathrm{CI})$ space. Finally, some vertical smoothing is applied to the resulting threshold profiles on a monthly, $1 \mathrm{~km}$, and $20^{\circ}$ latitudinal grid. In comparison with the constant CI threshold of 1.8 in Fig. 2, which is a robust choice for the detection of optically thick events, the new threshold profiles are more sensitive for the detection of optically thin cloud in the polar stratosphere, UTLS and free troposphere. 
Table 1. Cloud index microwindows (MW) and thresholds/acronyms.

\begin{tabular}{cccccc}
\hline MIPAS band & $\begin{array}{c}\mathrm{MW}_{1} \\
{\left[\mathrm{~cm}^{-1}\right]}\end{array}$ & $\begin{array}{c}\mathrm{MW}_{2} \\
{\left[\mathrm{~cm}^{-1}\right]}\end{array}$ & $\begin{array}{c}\text { CI threshold } \\
(\text { OPER_CI })\end{array}$ & $\begin{array}{c}\text { MIPAS based } \\
\text { threshold }\end{array}$ & $\begin{array}{c}\text { Gas index } \\
\text { (CIOPT_THRESH) }\end{array}$ \\
\hline $\mathrm{CI}-\mathrm{A}$ & $788.2: 796.2$ & $832.0: 834.4$ & 1.8 & (CI_THRESH) $^{*}$ & GI-A \\
$\mathrm{CI}-\mathrm{B}$ & $1246.3: 1249.1$ & $1232.3: 1234.4$ & 1.2 & - & GI-B \\
$\mathrm{CI}-\mathrm{D}$ & $1929.0: 1935.0$ & $1973.0: 1983.0$ & 1.8 & - & GI-D \\
\hline
\end{tabular}

( ): indicates the identifier of the CI detection method in the processor and in the analyses below.

*: the CI-THRESH method uses altitude, latitude and time-dependent threshold profiles.

\section{A more objective clear sky approach by model calculations (CIOPT_THRESH)}

In a second investigation, a simulation approach was used to calculate optimised thresholds that distinguish between clear sky and cloudy MIPAS CI values. In essence, these thresholds should be able to successfully separate cloud signatures from variable trace gas signatures. Here, the gas index (GI) is introduced as an index for each band (A, B, D and so forth) that describes the "trace gas only" signal in the radiances. This approach is independent of MIPAS data and allows a detailed analysis of the radiance variations expected in the primary MIPAS microwindows due to trace gas variability only.

Spang et al. (2004) already showed that the temperature dependence of the ratio is especially weak (e.g. $<1 \% / \mathrm{K}$ between 10 and $30 \mathrm{~km}$ for $\mathrm{CI}_{\mathrm{A}}$ ), but in the lower troposphere high water vapour amount (e.g $>1000 \mathrm{ppmv}$ for $\mathrm{CI}_{\mathrm{A}}$ ) can cause false detection results. Consequently, realistic water vapour variability must be taken into account when modelling GI values.

MIPAS cloud microwindows are simulated using the Oxford Reference Forward Model (RFM) (Dudhia et al., 2002). The model is set up in such a way that it takes into account the MIPAS FOV and the instrument line shape (ILS). Radiances are calculated in $1 \mathrm{~km}$ steps for each spectral region at the full spectral resolution of $0.025 \mathrm{~cm}^{-1}$ and calculations are performed with: (a) background trace gas and temperature estimates coming from the latitudinally dependent and seasonally varying climatology (Remedios et al., 2007); (b) aerosol is represented by latitude-dependent aerosol extinction profiles created from MIPAS extinction retrievals merged with a HALOE mid-latitude extinction profile; and (c) UTLS water vapour variability is represented by a range of water vapour concentration profiles calculated from the saturation mixing ratio profiles with climatological temperature and pressure profiles (Remedios et al., 2007). In addition, per latitude band and altitude step the maximum $\mathrm{H}_{2} \mathrm{O}$ from ECMWF re-analyses is used for a realistic representation of the large water variability in the modelled colour ratios (Sembhi et al., 2012).

The optimal GI is calculated as the minimum GI profile minus $3 \sigma$ where $\sigma$ is the noise equivalent spectral radiance

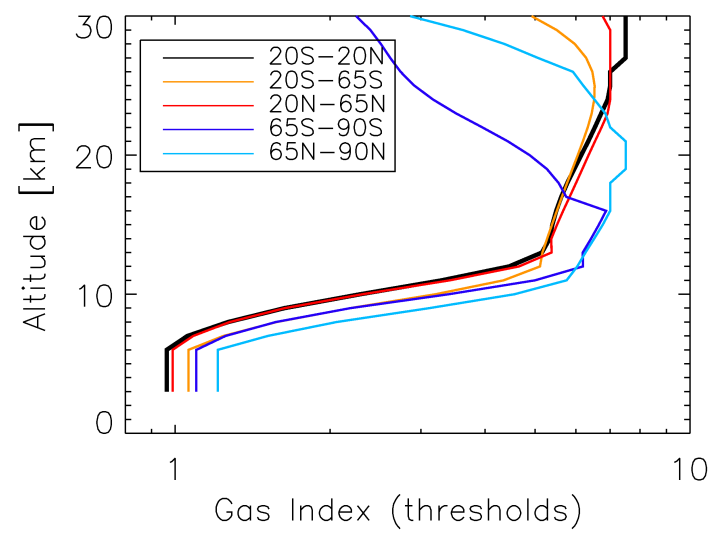

Fig. 3. Threshold profiles applied in the CIOPT_THRESH detection method of the MIPclouds processor (V1.6) based on the gas index analysis for MIPAS band A.

(NESR) propagating into each micro window:

$\mathrm{GI}_{\mathrm{opt}}=\mathrm{GI}_{\min }-3 \times \sigma$

Figure 3 shows the latitude- and altitude-dependent GI thresholds for band A.

\subsubsection{Singular value decomposition method}

The singular value decomposition (SVD) technique applied to MIPAS data is described in detail by Hurley et al. (2009). The basic principle is to establish a set of singular vectors SV (i.e. empirical orthogonal functions) which fit clear scenes, then extend this set to fit cloud-contaminated scenes, all based on simulated data. The first singular vector $\mathrm{SV}_{1}$ accounts for as much of the variability in the data as possible, and then each successive $\mathrm{SV}_{i}$ accounts for as much of the remaining variability as possible. An ensemble of RFM-simulated MIPAS spectra containing varying amounts of cloud have been used to define singular vectors which span the clear and cloudy atmospheric states (Hurley et al., 2009), called $\mathrm{SV}_{\text {clear }}$ and $\mathrm{SV}_{\text {cloudy }}$, respectively. The simulated spectra - and hence the singular vectors - cover the upper half of the MIPAS A band (a spectral range of 827.5$970 \mathrm{~cm}^{-1}$ ) because the bottom half of the MIPAS A band is characterized by strong gas lines. These singular vectors are defined for each tangent height in the MIPAS nominal scan 
pattern. Any arbitrary spectrum can be successfully fitted to a high degree using this set of altitude-dependent singular vectors which span the clear and cloudy atmospheric states.

Taking an arbitrary MIPAS IR spectrum $L_{\text {meas }}$, the first step is to normalise the spectra by subtracting the average radiance of $L_{\text {meas }}$. The linear least squares fit $L_{\mathrm{fit}}$ of this normalised spectrum is then trivially found, such that:

$L_{\text {fit }}=\sum_{i=1}^{m_{\text {clear }}} \lambda_{\text {clear }_{i}} \cdot \mathrm{SV}_{\text {clear }_{i}}+\sum_{i=1}^{m_{\text {cloudy }}} \lambda_{\text {cloudy }_{i}} \cdot \mathrm{SV}_{\text {cloudy }_{i}}$

Where $\lambda_{\text {clear }}$ and $\lambda_{\text {cloudy }}$ are constant coefficients of the least square fit. Once the linear least square fit has been obtained, the radiance components of the original signal can be reconstructed: the signal due to the clear background state $L_{\text {clear }}$ (defined by the left sum of Eq. 2) and that due to possible cloud presence $L_{\text {cloudy }}$ (right sum). The degree of cloud contamination is determined from the size of the coefficients of the cloudy vectors.

It follows, then, that when the radiance due to cloud presence becomes non-zero, a cloud is present. To normalise this quantity, the ratio of the cloudy radiance to the total radiance $L_{\text {total }}$, called the integrated radiance ratio, is considered such that when

$$
\frac{\overline{L_{\text {cloudy }}}}{\overline{L_{\text {total }}}}>0
$$

for cloudy spectra, where $\bar{L}$ represents the average of the reconstructed radiance in the $960-961 \mathrm{~cm}^{-1}$ microwindow. The logarithm of the integrated radiance ratio is the metric which is then used for the threshold in this method. Appropriate thresholds were chosen by application to MIPAS data from 2003 and are implemented in the processor (Spang et al., 2010a).

\subsubsection{Multi-wavelength continuum approach at $930-960 \mathrm{~cm}^{-1}$}

The background continuum radiance $R$ is determined in a number $(\sim 10)$ of microwindows in the atmospheric window region around $930-960 \mathrm{~cm}^{-1}$ by simple mean radiances for each radiance spectrum at each tangent height in a MIPAS scan below about $25 \mathrm{~km}$. Each microwindow contains one or two $\mathrm{CO}_{2}$ lines. These lines are masked for the computation of $R_{i}$ by precomputed molecular transmittance spectra based on climatological concentrations (Hurley et al., 2011). Given an a priori estimate of temperature, an estimate is made of the cloud effective fraction (CEF) $\alpha$ in each microwindow, which is effectively the continuum radiance expressed as the fraction of the radiance that would be expected if the entire FOV was filled with an opaque cloud (Hurley et al. 2009). Hurley et al. (2011) showed that

$\alpha=\frac{R}{B_{\mathrm{c}}}$ is a good approximation for CEF, with $R$ the continuum radiances and $B_{\mathrm{c}}$ the spectrally averaged Planck function corresponding to the cloud top temperature (CTT). Scattering from cloud particles can act to increase $R$ and $\alpha>1$ can be obtained from scattering clouds. In practice, MIPAS data do not show frequent examples of this and operationally CEF is set to 1 (Hurley et al., 2011). For the computation of $\alpha_{i}$ for a specific microwindow, it is sufficient to estimate CTT for $B_{\mathrm{c}}$ from the temperature of the corresponding altitude of ECMWF analyses. In a later stage of the processing, a more detailed multi-target retrieval of cloud top height, top temperature and extinction (CEX) is performed (see Sect. 3.2.2 and Hurley et al., 2011). A threshold value, e.g. a CEF of 0.1 , is then used to determine whether or not there is significant cloud contamination in this field of view. This is established independently for each microwindow and the level of confidence in the result is indicated by the consistency between microwindows, which is merely the number of cloudy flagged microwindows.

\subsubsection{Confidence of detection}

Each cloud detection method discussed above has its uncertainties. An individual cloud flag is defined for each analysed spectrum and each method of cloud detection. It was found that a combination of these results provides a more objective cloud decision and measure of confidence in the detection. For all methods, a certain weight is defined when combining the individual cloud flags depending on how well the different detection methods work in general. The confidence for a certain tangent height can be written as a weighted sum over all detection methods $\left(\mathrm{CD}_{i}\right)$ :

$\mathrm{CONF}_{\text {cloud }}=\sum_{i=1}^{n_{\mathrm{CD}}} \mathrm{FLAG}_{\mathrm{CD}_{i}} \cdot w_{\mathrm{CD}_{i}}$

This confidence is then normalised by the sum over all the weights $w_{\mathrm{CD} i}$ for those methods applied at the specific MIPAS spectrum. The weighting used in the data presented, Version 1.6, is summarised in Table 2. The resulting flag helps to decide how confident the cloud detection in a specific spectrum is. Optically very thin clouds will result in smaller confidence values due to the fact that not all methods are sensitive to these clouds. The weighting in Table 2 takes into account validation results of previous data versions. Currently, a single CONF value is normalised by the actual number of detection methods working at the specific altitude, which is not necessarily a constant number due to the fact that some methods only operate in a restricted altitude region (Table 2). In the altitude range of interest (6$30 \mathrm{~km}$ ), at least three methods should always operate.

In addition, classes of confidences - disputable, likely, very likely, and confident cloud - have been defined for each spectrum as illustrated in Table 3. For example, Fig. 4 shows a histogram of the specified confidence classes for March 
Table 2. Settings of the cloud confidence weighting and corresponding altitude range for all cloud detection methods.

\begin{tabular}{lll}
\hline Method & $\begin{array}{l}\text { Weighting } \\
w_{\mathrm{CD} i}\end{array}$ & $\begin{array}{l}\text { Altitude } \\
\text { range } \\
\mathrm{V} 1.6[\mathrm{~km}]\end{array}$ \\
\hline OPER_CI - A & 0.5 & $3-30^{*}$ \\
OPER_CI - D & 0.25 & $8-33^{*}$ \\
CIOPT_THRESH CI $_{A}$ & 0.5 & $3-33^{*}$ \\
CIOPT_THRESH CI $_{B}$ & 0.25 & $3-33^{*}$ \\
CI_THRESH & 0.5 & $4-33^{*}$ \\
SVD & 1.0 & $6-21$ \\
CEF (input for & $10 \times 0.1$ & $3-33^{*}$ \\
MACRO rtv.) & (for each MW) & \\
\hline
\end{tabular}

* upper altitudes of these methods are in some way extendable if the applicable altitude range in the processor is extended.

Table 3. Definition of cloud confidence classes.

\begin{tabular}{ll}
\hline $\begin{array}{l}\text { Normalised } \\
\text { cloud } \\
\text { confidence }\end{array}$ & $\begin{array}{l}\text { Confidence } \\
\text { class }\end{array}$ \\
\hline$\{0\}$ & clear sky/cloud-free \\
] $0,0.2[$ & disputable cloud \\
] $0.2,0.5[$ & likely cloud \\
] $0.5,0.8[$ & very likely cloud \\
{$[0.8,1.0]$} & confident cloud \\
\hline
\end{tabular}

2004 and June 2003. The cloud confidence distribution looks very similar for both months, where the "confident cloud" class is of roughly the same size as the sum over the three other less significant classes of cloud confidence ( $10 \%$ of all analysed spectra). Most spectra are classified as "clear sky" in the altitude range $3-33 \mathrm{~km}$ ( $>75 \%$ of $\sim 200000$ spectra).

In the profile-based count statistics for June 2003, about $80 \%$ of the profiles show one or more cloudy spectra somewhere in an altitude scan. This value can be used as a rough estimate of the total amount of global cloud between 3 and $33 \mathrm{~km}$ measured with MIPAS. It is in surprisingly good agreement with the total cloud amount retrieved from the CALIPSO satellite with active measurements of the Cloud-Aerosol Lidar with Orthogonal Polarization (CALIOP) (Stubenrauch et al., 2010, Table 2). This is currently thought to be the most sensitive sensor for the detection of clouds from space. When considering only the uppermost layers of the clouds and including SVCs, Stubenrauch et al. (2010) identified a cloud amount of $80 \%$. Their results include clouds below $3 \mathrm{~km}$ (not covered by MIPAS) and represent a climatological mean from 2007 to 2008. The analysis of Stubenrauch et al. (2010) differentiates low-level, middle-level, and high-level cloud amounts (LCA, MCA, HCA). These amounts are defined by cloud top pressure $p_{\text {cld }}>680 \mathrm{hPa}(\sim 3 \mathrm{~km}), 680>p_{\text {cld }}>440 \mathrm{hPa}$ $(\sim 6 \mathrm{~km})$, and $p_{\text {cld }}<440 \mathrm{hPa}$, respectively. Stubenrauch et al.
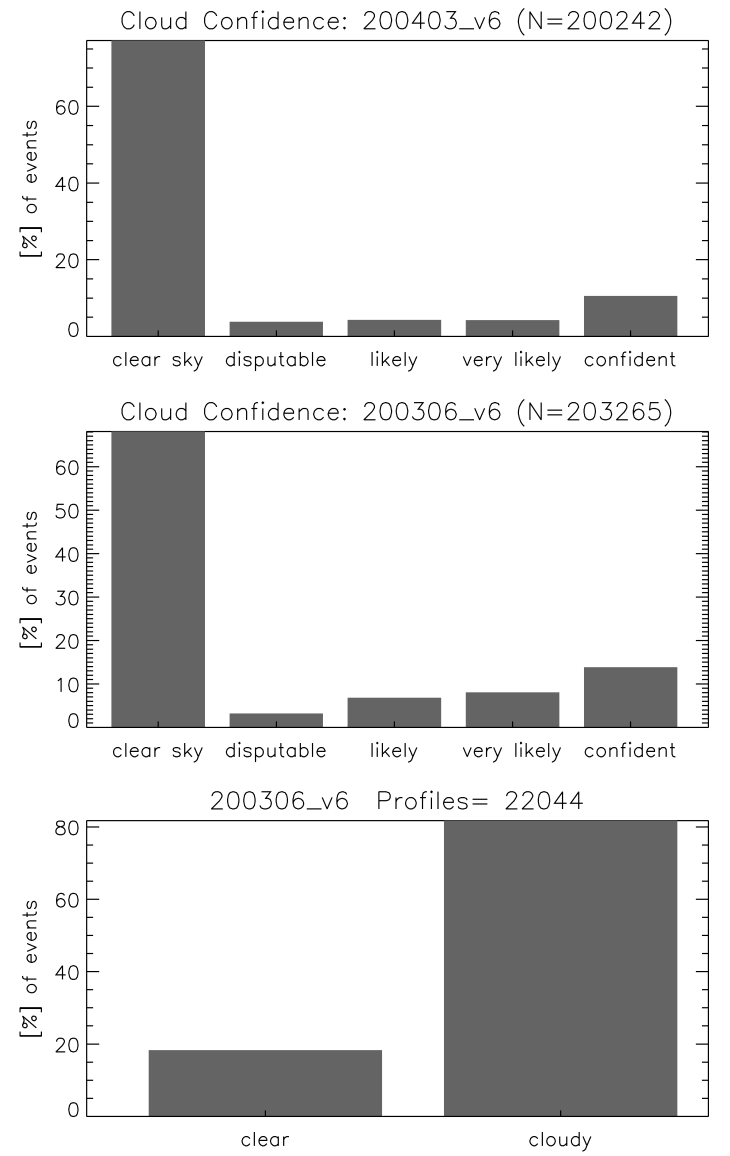

Fig. 4. Probability distribution in percentage of the normalised cloud confidence classes (for definition $s$, Table 3 ) for all spectra analysed for March 2004 (top) and June 2003 (middle) in the altitude range 3 to $33 \mathrm{~km}$. The bottom figure shows the corresponding number of cloudy and non-cloudy profiles for the June 2003 distribution shown above.

found that HCA accounts $50 \%$, MCA for $12 \%$, and LCA for $38 \%$ of all clouds. This results in a CALIPSO cloud amount of only $\sim 50 \%$ above $3 \mathrm{~km}$ altitude, not accounting for multilayer clouds. The significant difference to MIPAS may arise as the probability of detecting a cloud along the MIPAS LOS (300-400 km) is quite large in comparison with the extremely small footprint $(90 \mathrm{~m} \times 90 \mathrm{~m})$ of the lidar instrument. However, it is also possible that CALIPSO underestimates the cloud amount for optically thin cirrus clouds as suggested by Davis et al. (2010). Care should be taken when comparing quantities like cloud amount, cloud cover or occurrence frequencies of different sensors, especially between limb and nadir measurements. Specific adaptations in the analysis are necessary for each instrument to make quantities comparable (see also Sect. 4). 


\subsection{Cloud macrophysical parameters}

\subsubsection{Simple estimate of CTH, CTT and CTP}

Cloudy spectra detected by the different detection methods are directly linked to a corresponding altitude or engineering height of the tangent point. This defines the first guess cloud top height (CTH) for each colour ratio, SVD, and multiwavelength continuum method. The corresponding cloud top pressure (CTP) and cloud top temperature (CTT) are determined from the ECMWF re-analyses at the coincident location of the CTH. The altitude correction described in the supplement material is taken into account. The resulting CTHs have an uncertainty in the order of half of the vertical FOV (i.e. $\sim 1.5 \mathrm{~km}$ ), because the vertical sampling is in the same order of magnitude like the FOV. Higher resolved information for CTH, where the altitude of the cloud top is located relatively in the FOV, would substantially improve the quality of the CTH as well as for the other derived parameters, CTP and CTT. This improvement has been realised in an optimal estimation retrieval and is described in the next section.

For a simple use in scientific applications, combined (summary) information of all methods for each macroscopic parameter (CTH, CTP, and CTT) is an output of the processing (variable prefix: SUM_CLOUD). Currently, these parameters are dominated by the optimal estimation retrieval result. If there is a successful retrieval then this is used for the SUM_CLOUD information, if this is not the case then weighted CTH information of all other detection methods is applied in a manner similar to the cloud confidence parameter in Sect. 3.1.4. The SUM_CLOUD information is part of an ongoing optimisation procedure for the definition of the best possible combination of different detection methods based on the validation results (see Sect. 5).

\subsubsection{Optimal estimation retrieval for CTH, CTT and cloud extinction}

The optimal estimation retrieval for CTH, CTT and extinction (CEX) based on a simple continuum fit has been developed and is described in detail in Hurley et al. (2011). The cloud effective fraction (CEF) method briefly introduced in Sect. 3.1.3 is applied to establish where the cloud top is located in the relatively large vertical field of view of MIPAS (3-4 km). Using the continuum radiance in this and the adjacent fields of view above and below, as well as an a priori estimate of temperature and the retrieved CEF, a retrieval is then performed of cloud top height (CTH), cloud top temperature (CTT) and cloud extinction (CEX). The retrieval forward model assumes a simple homogeneous cloud acting as a grey absorber but with a vertical temperature gradient determined by the a priori temperature profile and no other atmospheric absorption or emission (justified by the use of continuum radiances as input). The radiances of pencil beams can be modelled using a relatively simple radiative transfer calcu- lation and these are then convolved with the instrument field of view to predict the observed continuum radiances. The retrieval adjusts the three parameters (CTH, CTT, CEX) until the best fit to the measurements and the a priori estimates is obtained. Results from the 10 microwindows are combined and the scatter used to establish the uncertainty in the results. Finally, the optimal estimation retrieval results in an improved representation for $\mathrm{CTH}$ and CTT compared to the simpler SVD or cloud index approach by taking into account the relatively large field of view of the instrument $(3 \mathrm{~km})$.

\subsection{The cloud scenario database}

A comprehensive cloud scenario database (CSDB) containing modelled MIPAS radiance measurements in the presence of various cloud types and related Jacobians with respect to cloud microphysical parameters and interfering variables was compiled. Currently, the database contains more than 70000 different cloud scenarios and more than 600,000 cloud spectra for PSC (liquid supercooled ternary solutions (STS), solid nitric acid trihydrate (NAT), and ice), cirrus and liquid water clouds (Spang et al., 2008). To our knowledge, this is the first time that such extensive simulations have been performed for mid-IR limb-emission sounding of clouds. Constraints such as selected regions for algorithms of previous studies and atmospheric window regions with small gas contribution were taken into account and resulted in the following optimised list of window regions, in total a range of $137 \mathrm{~cm}^{-1}$, for the database: 782-841, 940-965, 1224-1235, 1246-1250, 1404-1412, 1929-1935, 1972-1985, 2001-2006, and 2140-2146 $\mathrm{cm}^{-1}$.

All CSDB spectra were generated with the Karlsruhe Optimized and Precise Radiative transfer Algorithm (KOPRA) model (Stiller, 2000), which takes single scattering into account (Höpfner, 2004). Input parameters such as effective radius, volume density (or IWC), cloud types and composition (e.g. three $\mathrm{H}_{2} \mathrm{SO}_{4} / \mathrm{HNO}_{3}$ compositions for STS: $02 / 48$, $25 / 25$, and $48 / 02$ with $50 \% \mathrm{H}_{2} \mathrm{O}$ ) as well as cloud top and bottom height were varied for the database. In addition, various background atmospheres for temperature and the major trace gas emitters in the corresponding wavelength regions are accounted for. The KOPRA results were compared with multiple scattering calculations of the FM2D/SHDOM model (Kerridge et al., 2004). The conclusions from these simulations are (Spang et al., 2008): (a) multiple scattering is important for intermediate cloud optical thickness, but good agreement is found for optically thin and optically thick clouds; (b) radiance differences introduced by multiple scattering are generally within the range of other uncertainties affecting cloud radiative transfer (about $2-5 \%$ at $950 \mathrm{~cm}^{-1}$ but significant larger 20-50\% differences at $2000 \mathrm{~cm}^{-1}$ ); (c) consideration should be given to the effect of solar scattering (for daytime retrievals) in the short wave. 


\subsection{Cloud type classification}

Multicolour ratios were successfully used for the classification of PSC types (Spang et al., 2002; Höpfner et al., 2006a, b) with IR limb measurements. Brightness temperature differences (BTD) are typically applied for nadir sounders for the differentiation of tropospheric aerosol and water cloud types (e.g. Li et al., 2003). In the MIPclouds processor, a combination of the best suited BTD and colour ratios is implemented together with a statistical multi-BTD approach. The latter method is a simple probabilistic classifier based on the application of Bayes' theorem with strong ("naive") independence assumption (Hanson et al., 1991). The CSDB was used to develop and train the algorithms. The method selects the best micro window pairs (up to 10) by optimising the product probability of the probability density distribution of all potential BTDs for $1 \mathrm{~cm}^{-1}$ broad MWs from the CSDB. The following cloud types can be classified: (a) polar stratospheric cloud types: ice, nitric acid trihydrate and supercooled ternary solution droplets, (b) cirrus (cir) and liquid (liq) clouds in the free troposphere and upper troposphere and lower stratosphere. A more detailed description of the classification can be found in the supplement material.

\subsection{Microphysical parameters}

Retrieval studies on potential microphysical parameter retrieval based on Jacobian spectra as part of the CSDB showed that the MIPAS spectra contain sufficient information on quantities such as IWP and effective radius ( $\left.R_{\text {eff }}\right)$ for full radiative transfer retrieval (single scattering) with three or four wavelength regions with respect to the noise error. However, realistic retrievals need to include scattering processes with sufficient accuracy and this approach was not realistic for a processing system with NRT capability. As a consequence, a retrieval of simpler estimates such as $R_{\text {eff }}$, the limb IWP, and the parameter surface area density path (ADP) has been investigated and the estimates are currently at the validation phase (see Sect. 4).

The current processor retrieves $R_{\text {eff }}$ and ADP for the top three altitudes of cloudy spectra of the MIPAS measurement profile. This restriction is applied because tangent heights below are difficult to penetrate. A quantitative separation of cloud effects in the actual tangent height spectrum from emissions of cloudy layers above is not achievable with the current approach. Based on $R_{\text {eff }}$ it would be possible to determine the limb IWP (ADP is proportional to product of limb IWP and $R_{\text {eff }}$ ), but this has not yet been implemented.

\subsubsection{Surface area density path}

With respect to infrared emission in the limb geometry, the absorption and extinction characteristic of a cirrus cloud is mainly dominated by the particle surface area density integrated along the optical path (ADP). For example, analyses with the CSDB show that MIPAS band A cloud index $\mathrm{CI}_{\mathrm{A}}$ is very well correlated with ADP and could be easily retrieved from the data. The surface area density $(A)$ is defined as:

$A=\frac{3 \cdot V}{R_{\mathrm{eff}}}$

with $V$ : volume density typically in $\left[\mu m^{3} / \mathrm{cm}^{3}\right]$ and $R_{\text {eff }}$ : the effective radius in $[\mu \mathrm{m}]$ of the particle size distribution, and $A$ typically in $\left[\mathrm{\mu m}^{2} / \mathrm{cm}^{3}\right]$. The relation is exactly correct only for spherical particles. The quantities necessary to calculate $A$ for the modelled spectra are defined in the CSDB. The area density path is the integrated area density from the observer to the tangent point and to deep space:

$\mathrm{ADP}=\int_{\mathrm{obs}=0}^{\infty} A d x\left[\mu \mathrm{m} \mathrm{cm}^{-2}\right]$

This approach eliminates the uncertainty in where the cloud is located along the limb path and how large the horizontal extent of the cloud is. Therefore, ADP is a useful quantity for comparisons with global models where the limb path can be traced through the model output to generate the ADP quantity. Note that $A$ is linked to the limb IWP by Eq. (3) and (4) to:

$$
\begin{aligned}
\text { IWP } & =\int_{\mathrm{obs}=0}^{\infty} \operatorname{IWC} d x=\int_{\mathrm{obs}=0}^{\infty} V \cdot \rho_{\text {ice }} d x \\
& =\frac{1}{3} \int_{\mathrm{obs}=0}^{\infty} A \cdot R_{\mathrm{eff}} \cdot \rho_{\mathrm{ice}} d x,
\end{aligned}
$$

with $\rho_{\text {ice }}$ the mass density of ice, and for a homogeneous limb path segment ADP becomes:

$\mathrm{ADP}=3 \cdot \operatorname{IWP} /\left(R_{\text {eff }} \cdot \rho_{\text {ice }}\right)$

Figure 5 shows an example for the relation between $\mathrm{CI}_{\mathrm{A}}$ and the limb-integrated IWP (equivalent to the integrated volume density) for tropical cirrus cloud spectra at $14 \mathrm{~km}$ altitude of the CSDB. For optically thin conditions $\left(\sim 1.3<\mathrm{CI}_{\mathrm{A}}<7\right)$, a large scatter becomes obvious, but with a strong dependency on radius (colour code). A scaling of IWP by $R_{\text {eff }}$ or the use of ADP, which is equivalent to the scaling, results in a very compact correlation between $\mathrm{CI}_{\mathrm{A}}$ and $\mathrm{ADP}$ (Fig. 6), and $\mathrm{CI}_{\mathrm{A}}$ can be used as an excellent proxy for ADP. The method is only weakly sensitive to the background atmosphere (seasonal changes), but shows a significant dependency with altitude (not shown). The correlation between ADP and $\mathrm{CI}_{\mathrm{A}}$ is currently implemented in the retrieval for cirrus clouds and ice PSC. The 4th order polynomial fitting parameters for $\mathrm{ADP}\left(\mathrm{CI}_{\mathrm{A}}\right)$ are filed in altitude-dependent look-up tables. A similar approach can be applied for the volume density path (VDP) for clouds where small particles dominate the size distribution. This has been applied for STS and NAT, where 


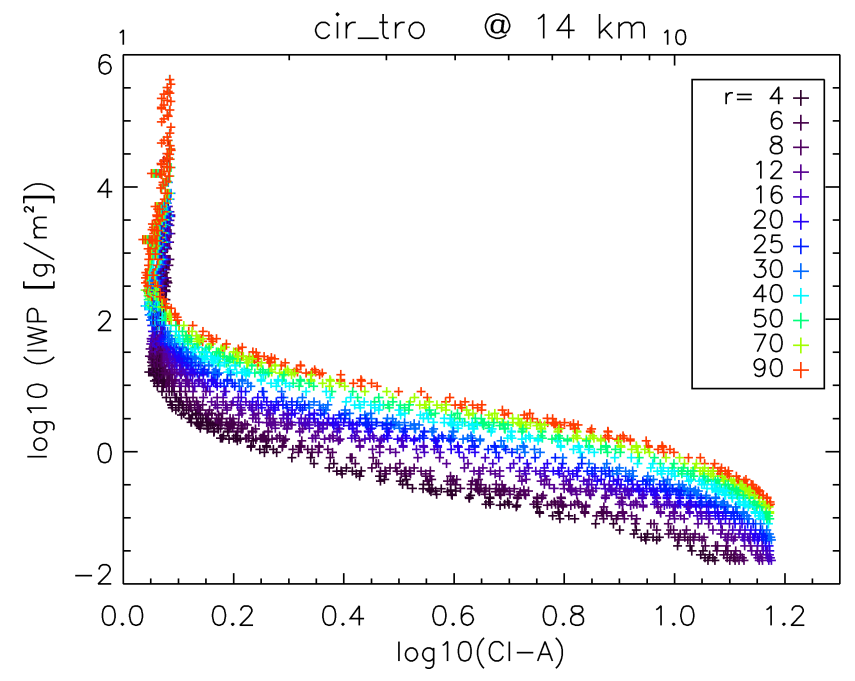

Fig. 5. Correlation diagram between $\mathrm{CI}_{\mathrm{A}}$ and the cirrus IWP (both parameters in $\log _{10}$ space) for tropical CSDB spectra at $14 \mathrm{~km}$ altitude. The varying effective radius in units of $\mu \mathrm{m}$ is colour coded.

the results for the CSDB showed a more compact correlation than for ADP. The latter differentiation of the cloud types with respect to VDP and ADP highlights the well-known fact that for small particles the extinction is proportional to the volume density and for large particles to the area density.

The saturation of ADP with respect to $\mathrm{CI}_{\mathrm{A}}$ in Fig. 6 can be used to specify a detection limit for optical thick conditions when the spectra are saturated and $\mathrm{CI}_{\mathrm{A}}$ tends to converge against a value $\sim 1.1$ (in Fig. 6): $\log _{10}\left(\mathrm{CI}_{\mathrm{A}}\right) \sim 0.05$ ). This is the ratio of the black body emissions at the two wavenumber regions used in the colour ratio, and where it is not possible to retrieve a reliable ADP by the method described above. The upper ADP threshold is typically in the range of $8.5<\log _{10}$ (ADP) $<9$ (ADP in $\mu \mathrm{m}^{2} \mathrm{~cm}^{-2}$ ) depending on altitude and background atmosphere.

\subsubsection{An estimate for effective radius}

Results of the $R_{\text {eff }}$ retrievals are not part of the validation section. Therefore the method is described only briefly to give a complete overview of the parameters retrieved with the processor.

From the definition of Aand ADP it is crucial to obtain information on $R_{\text {eff }}$ from the measurement to make it possible to compute the limb IWP. It has been shown by means of radiative transfer simulations that MIPAS observations of (optically thin) clouds are generally sensitive to particle effective radii in the range between $\sim 0.8-30 \mu$ m (Spang et al., 2008). In the case of smaller particles it is not possible to distinguish between different sizes since the measured radiance is only sensitive to the total particle volume density. For larger particles, the limb radiance depends mainly on the total particle surface density.

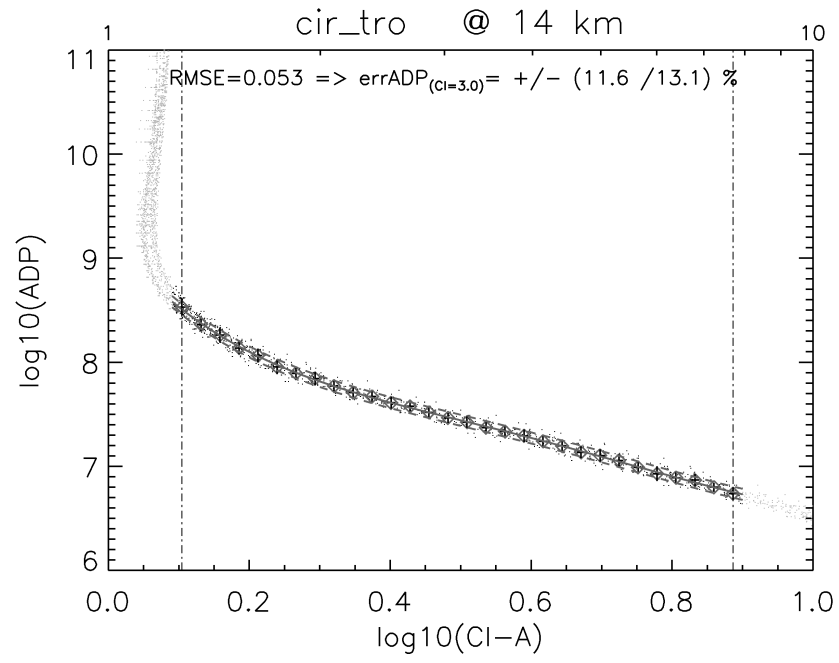

Fig. 6. Correlation diagram between $\log _{10}\left(\mathbf{C I}_{\mathrm{A}}\right)$ and $\log _{10}(\mathrm{ADP})$ with ADP in $\mathrm{m}^{2} \mathrm{~cm}^{-2}$ for tropical CSDB spectra at $14 \mathrm{~km}$ tangent height (dots). Roots mean square error bars with respect to a fitted 4 th order polynomial are superimposed.

The implemented method of estimating particle radius from MIPAS cloud observations is based on a least-squares comparison of MIPAS infrared limb radiance data in selected spectral regions with simulated radiances form the CSDB. This method was chosen since there is no unambiguous and simple dependence of radiance on radius. However, the currently employed method has its limitations. Modelled IR spectra based on well-defined particle size distributions and microphysical parameters were fed into the processor for blind test retrievals (for details of the setup of the blind test retrieval see Sect. 4.2). First results of the comparison show a significant low bias in the retrieved $R_{\text {eff }}$ values compared to the input. Possible reasons for the bias are: (1) the limited range of atmospheric conditions simulated within the CSDB; (2) the degree of realistic cloud simulations within the database, especially related to effects of neglecting cloud inhomogeneity and multiple scattering (both effects are considered in the blind test data); (3) an inability to distinguish between homogeneous, optically thin cloud layers which entirely fill the instrument's field of view and inhomogeneous scenes. Further investigations will be necessary to improve the quality of the $R_{\text {eff }}$ retrieval for scientific applications, for example to quantify the impact of the effects above and to rule out potential other error sources.

\section{Validation on simulated data}

A new dataset of simulated cloudy and non-cloudy radiances for various cloud geometries and parameters as well as microphysical properties was created for the validation of the processor by the blind test retrieval (BTR) approach. The radiative transfer simulations were made using a 2-D radiative 
transfer model with multiple scattering calculations and are based on cloud fields selected from ECWMF analysis data (Kerridge et al., 2004). The modelled spectra include the impact of the finite horizontal extent of clouds, their potential displacement far from the tangent point along the line of sight (LOS), the spatial variation of cloud parameters within the clouds, and multiple cloud fragments within the atmosphere which all scatter into the line of sight. The modelled radiances were used as input to the retrieval code. The resulting BTR parameters are evaluated in comparison with the original cloud field parameter, the so-called "true state" (e.g. for IWC, IWP, $R_{\text {eff }}$ or ADP).

\subsection{Forward model simulations}

Simulations were based on transects through 2-D atmospheres, with parameters allowed to vary along track to simulate realistic changes along the MIPAS line of sight. The final output of the forward model calculations was a set of MIPAS radiance profiles at various locations throughout the 2-D atmosphere.

The simulations were performed using a combination of two models: SHDOM, and elements of the Rutherford Appleton Laboratory (RAL) line-by-line radiative transfer model FM2D. The SHDOM model (Evans, 1998a) is able to calculate the complete scattered radiance field for a 3-D scattering atmosphere, but has not been designed for limb sounding radiances and neglects spherical geometry. Hence it was necessary to combine this model with the ray tracing ability of FM2D (Kerridge et al., 2004).

The combined FM2D/SHDOM model runs consisted of a number of steps: (1) Calculations were performed to obtain the optical properties of the cloud, along with the trace gas absorption coefficients for all grid points along the 2D transect. (2) SHDOM was then used to calculate the 2D source function. (3) This was then integrated along each MIPAS line of sight (neglecting refraction) to output pencil beam spectra at a fine vertical grid for each tangent point profile. (4) Spectra were convolved with the MIPAS instrument line shape. (5) A field-of-view convolution was performed to output spectra on MIPAS tangent heights. The original spectra without field-of-view convolution were also provided as output.

\subsection{Setup of various cloud scenarios}

The basic data used to define the cloud fields for the simulations came from ECMWF operational analysis data for 22 July 2007, 00:00 UT. North-south transects of the data were examined for potentially suitable and varying cloud scenarios. One requirement for selecting the data was that there should be sufficient high ice clouds with thicknesses within the range to which MIPAS is expected to be sensitive. All scenarios (transects) include regions where ice and liquid wa- ter clouds are both present in the same ECMWF grid box (usually at altitudes below $5 \mathrm{~km}$ ).

The cloud parameters given by the ECMWF operational analysis include the mass mixing ratio of liquid-water and ice within the model box, and the fraction of the cloud model box occupied by cloud. Additional optical parameters required by the forward model were taken from optical models based on Mie theory for liquid cloud and aggregate particles for cirrus (Baran et al., 2001). The effective radius for the ice particles was calculated using a correlation with the ice water content as described by Evans et al. (1998b) (with a minimum value of $10 \mu \mathrm{m}$ ). The liquid water effective radius was assumed to have a constant value of $10 \mu \mathrm{m}$. The sum optical properties for liquid and ice particle (extinction coefficients, phase function, etc.) are computed based on the sampling of the ECMWF grid. These optical properties are input to the radiative transport model, allowing mixtures of liquid and ice at a given point along the line of sight as well as the integration or weighted means along the line of sight. Background temperatures, pressures and the ozone and water vapour fields were also taken from the ECMWF data and varied across the scenario. Other trace gas concentrations were set to climatological values. A constant background aerosol extinction profile was also used.

Three scenarios were selected. Scenario 1 represents midlatitude clouds for a latitude range between $40-60^{\circ} \mathrm{N}$ and Scenario 2 and 3 are two typical tropical cloud structures for a latitude range between $10^{\circ} \mathrm{S}-25^{\circ} \mathrm{N}$ and $20^{\circ} \mathrm{S}-10^{\circ} \mathrm{N}$, respectively, with horizontally extended and smaller scale cirrus layers and high-reaching convective systems.

Figure 7 shows the IWC distributions for Scenarios 1 and 2. The output from the simulation was the simulated radiance spectra for the spectral microwindows used in the retrieval of the processor along with the "true state" of the atmosphere at the tangent point, like pressure, temperature, and the cloud parameters required for validation. These included a limbintegrated ice water path, liquid water path, optical depth, an approximate 'limb ice effective radius' obtained by an integration of $R_{\text {eff }}$ weighted with IWC along the line of sight.

For each scenario, three different sets of results were provided. Firstly, a set without convolution of the field of view (on $0.5 \mathrm{~km}$ vertically spaced pencil beams) - the highresolution BTR input, and then two sets with field-of-view convolutions - the MIPAS resolution BTR input, looking at different tangent altitudes grids e.g. $6,9,12 \ldots \mathrm{km}$, and $4.5,7.5,10.5 \ldots \mathrm{km}$, respectively (FOV1 and FOV2). This approach further extended the number of validation test profiles for each scenario without additional computational effort. In total, 215 profiles for the high resolution and 430 profiles for the MIPAS resolution blind tests were prepared, where the majority of profiles are influenced by cloud radiation in a certain altitude region. A small fraction of clear sky profiles is also included $(<5 \%)$. 


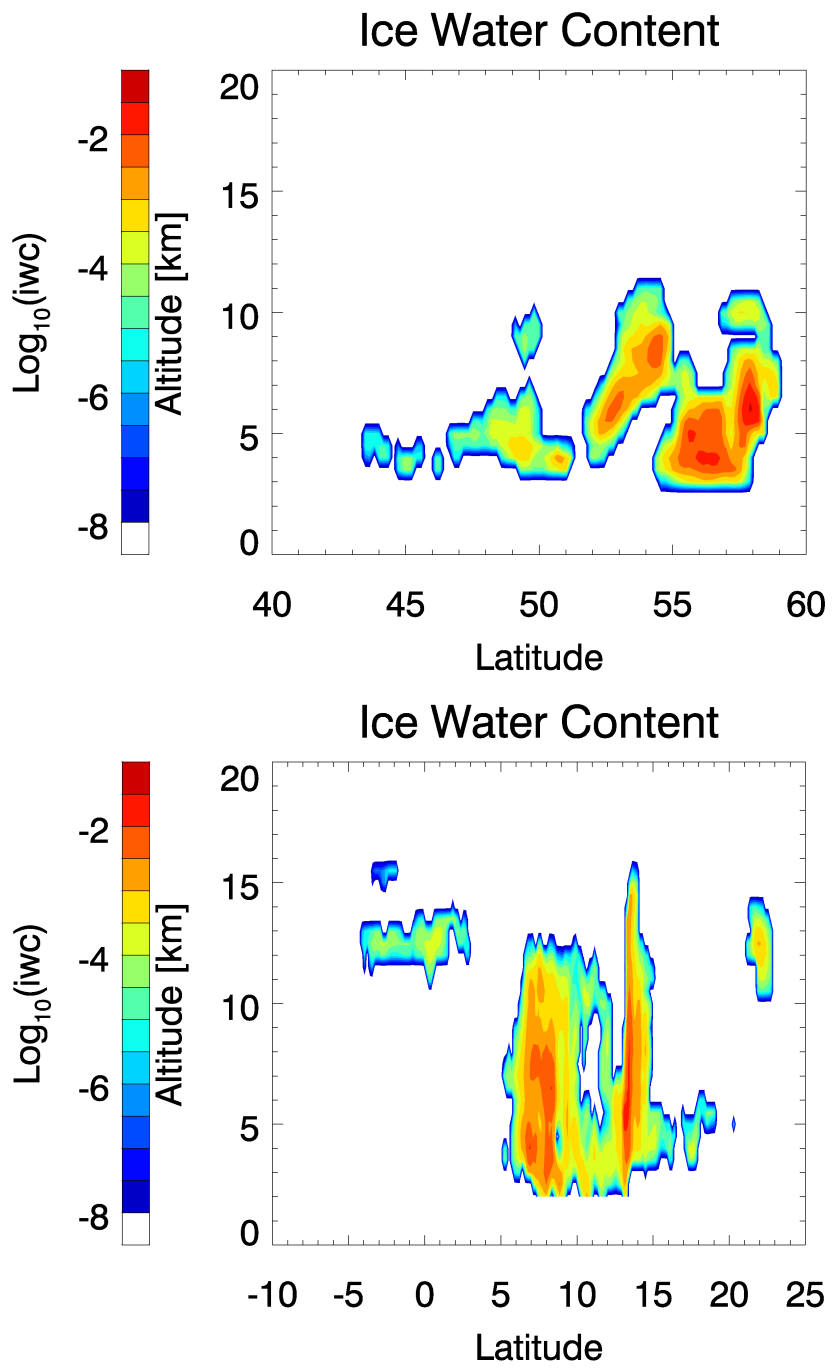

Fig. 7. Latitude-altitude cross section of ice water content in $\mathrm{g} \mathrm{m}^{-3}$ and $\log _{10}$ scale from ECMWF data. These data were input to the radiative transfer calculation with FM2D/SHDOM for Scenario 1 and 2 (top/bottom: mid and tropical latitudes).

\subsection{Results on cloud detection}

Cloud detection methods can be validated by comparison with various sensors of retrieved cloud top heights and corresponding cloud climatologies (see next section). However, the validation with coincident observations between sensors - the most stringent method - is a difficult task, due to different detection sensitivities and viewing geometries (e.g. limb and nadir, or field of view). The blind test data (modelled limb radiances) and the related input parameters of the forward model (e.g. temperature, limb-integrated IWP, retrieved parameters such as the area density path based on the ECMWF IWC and LWC data) can be used as a reference to quantify the quality of the detection methods introduced in Sect. 3.

\subsubsection{Comparison of different detection methods}

Figure 8 shows examples of the limb-integrated area density path for Scenarios 1 and 2 computed from the 2-D transects of IWC from ECMWF and the estimated $R_{\text {eff }}$ for the FM2D/SHDOM input, which can be described as the "true state" ADP of the atmosphere for the blind test approach. The top figures show results for the original grid of the radiative transfer calculations with a vertical resolution of $500 \mathrm{~m}$, which is representative of a virtual instrument with $500 \mathrm{~m}$ vertical FOV. The lower panels present the BTR results for input spectra with realistic MIPAS vertical resolution and vertical sampling $(3 \mathrm{~km})$. The two kind of datasets for high resolution (HR) and MIPAS resolution (MR) BTR are described below. Each colour-coded box centred at a specific altitude grid point represents the integrated surface area density along the limb path at the corresponding observation tangent height (illustrated by one example of a limb path for a tangent height of $8 \mathrm{~km}$ in Scenario 1 in the MR-BTR). For larger profile statistics, a significantly higher horizontal sampling was applied to the model fields compared to the original MIPAS data (typically $3-4^{\circ}$ in latitude), which does not affect the following analyses.

The effect of using more realistic 2-D cloud distributions instead of idealised 2-D-homogeneity becomes obvious when comparing the original IWC fields (Fig. 7) and the limb-integrated "true state" ADP fields (Fig. 8). Even small extended cirrus layers as in Scenario 2 (at $\sim 12 \mathrm{~km}$ and between $-5^{\circ}$ and $2^{\circ}$ latitude) affect a significantly larger area of potential limb measurements in the horizontal and vertical domain than suggested by the IWC distribution. This will cause an overestimation in the deduced means of cloud parameters such as occurrence frequencies, coverage or cloud amount. Consequently, special adaptations to the analyses are necessary when comparing these parameters, for example, with nadir looking instruments (e.g. Liao et al., 1995, see also Sect. 5). This specific caveat with limb measurements is described in the following by the limb-smearing effect.

CTHs retrieved with a subset of methods of the processor are superimposed in Fig. 8 and give an indication of the detection sensitivity of each method with respect to the optical thickness of the cloud, here illustrated by the parameter ADP. Unfortunately, it was not possible to validate the SVD method with the blind test approach. Due to the relatively large wavenumber range necessary for the SVD method (Hurley et al., 2009) compared to the other detection methods, the computation time of the forward model for the creation of an adequate dataset would have been too long for the time frame of this study.

The summary information of all detection methods - the SUM_CLOUD parameter introduced in Sect. 3.2.1 - is added in Fig. 8 (as crosses). As already mentioned, this parameter is dominated by the macro retrieval result. All the methods provide consistent results for the high-resolution case with high detection sensitivity (Fig. 8, top plates). This is 

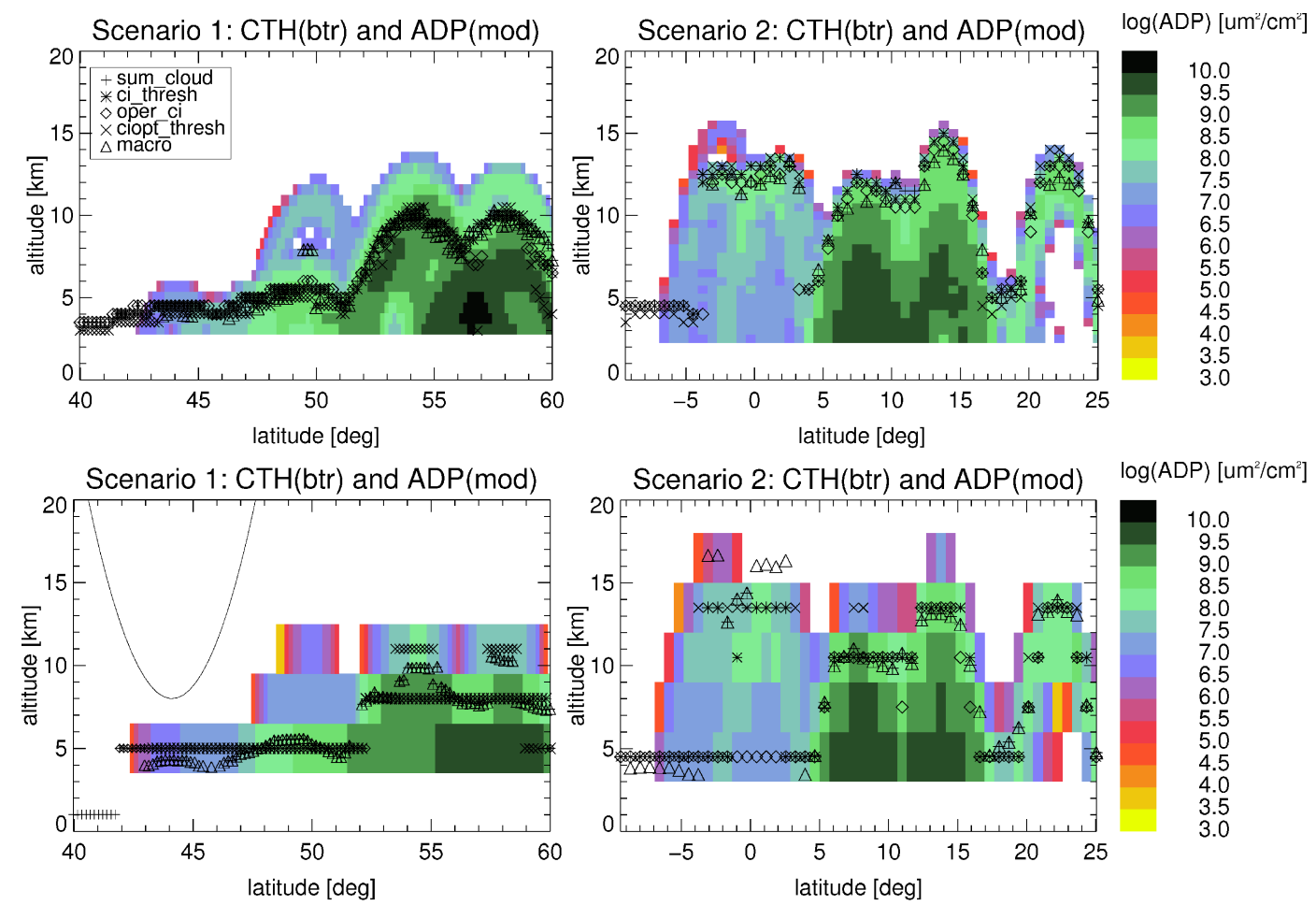

Fig. 8. Colour-coded area density path $\left(\mathrm{ADP}_{\mathrm{mod}}\right)$ of the so-called "true state" of the cloudy atmosphere presented for latitude versus altitude, computed from the corresponding IWC distribution of Fig. 7 and effective radius information along the line of sight. No field of view is applied for the top panels and a MIPAS field of view of $3 \mathrm{~km}$ is convolved for the lower panels. Blind test retrieval (btr) results of CTH for various detection methods of the processor are overlaid (black symbols). CTHs at $1 \mathrm{~km}$ altitude indicate non-cloudy conditions based on the retrieval. Each colour-coded ADP box represents the integrated ADP along a limb path with a corresponding tangent height in the centre of the box. Superimposed in Scenario 1 with MIPAS FOV is a typical limb path for a tangent height of $8 \mathrm{~km}$.

also a valuable finding for the proposed limb-imaging technique (Riese et al., 2005; ESA, 2008) that will utilise FOVs with a vertical extension similar to the high-resolution case. CTHs rarely differ by more than $500 \mathrm{~m}$ for Scenario 1 and slightly more for the tropical case. This highlights generally similar detection sensitivities for all the methods. In addition, the CTHs of a specific method seem to be coincident with roughly constant ADP values, which make it possible to quantify an objective detection sensitivity by the ADP approach (see below). ADP values smaller than $10^{7} \mu \mathrm{m}^{2} \mathrm{~cm}^{-2}$ are rarely detected.

Obviously, differences become larger between the methods when considering the MIPAS FOV. The OPER_CI and CI_THRESH methods detect a lower cloud top than the macroscopic parameter retrieval and CIOPT_THRESH for some profiles. In the HR case, the latter method already showed the highest cloud tops in the upper troposphere and there is also a tendency to underestimate cloud tops in the lower troposphere $(<7 \mathrm{~km})$ compared to the other methods.

However, cloud tops are also detected in both scenarios where the "true state" ADP shows no indication of cloud effects. The events at $40^{\circ}-43^{\circ}$ latitude (Scenario 1 ) and $-10^{\circ}$ to $-7^{\circ}$ (Scenario 2 ) for altitudes below $6 \mathrm{~km}$ are generally caused by liquid clouds, as can be confirmed by analysis of the ECMWF LWC fields. The slightly overestimated cloud tops for Scenario 2 in the FOV case between $0^{\circ}$ and $4^{\circ}$ latitude are artefacts caused by the macro retrieval and are only observed at this location and this specific vertical sampling and not in the $1.5 \mathrm{~km}$ shifted FOV sampling (not shown).

The mid-latitude BTR with MIPAS resolution shows very nicely the advantages of macro retrieval. In the coarsely resolved MIPAS FOV the retrieved cloud top locations give an excellent estimate of the 'real' and more realistic cloud top evolution along the latitude cross section, which becomes apparent when results are compared with high-resolution ADP distribution and CTHs.

\subsubsection{Quantification of detection sensitivity by ADP}

Each detection method has limited sensitivity. Figure 8 shows qualitatively for all the methods that limb paths with ADP $<10^{6}-10^{7} \mu \mathrm{m}^{2} \mathrm{~cm}^{-2}$ are not detectable, even in the high resolution BTR which are representative of a limb sounder with much better vertical resolution and sampling than MIPAS. For a more quantitative definition of detection sensitivity we used the probability distributions of the modelled "true state" ADP values ( $\left.\mathrm{ADP}_{\text {mod }}\right)$ at the detected CTH 

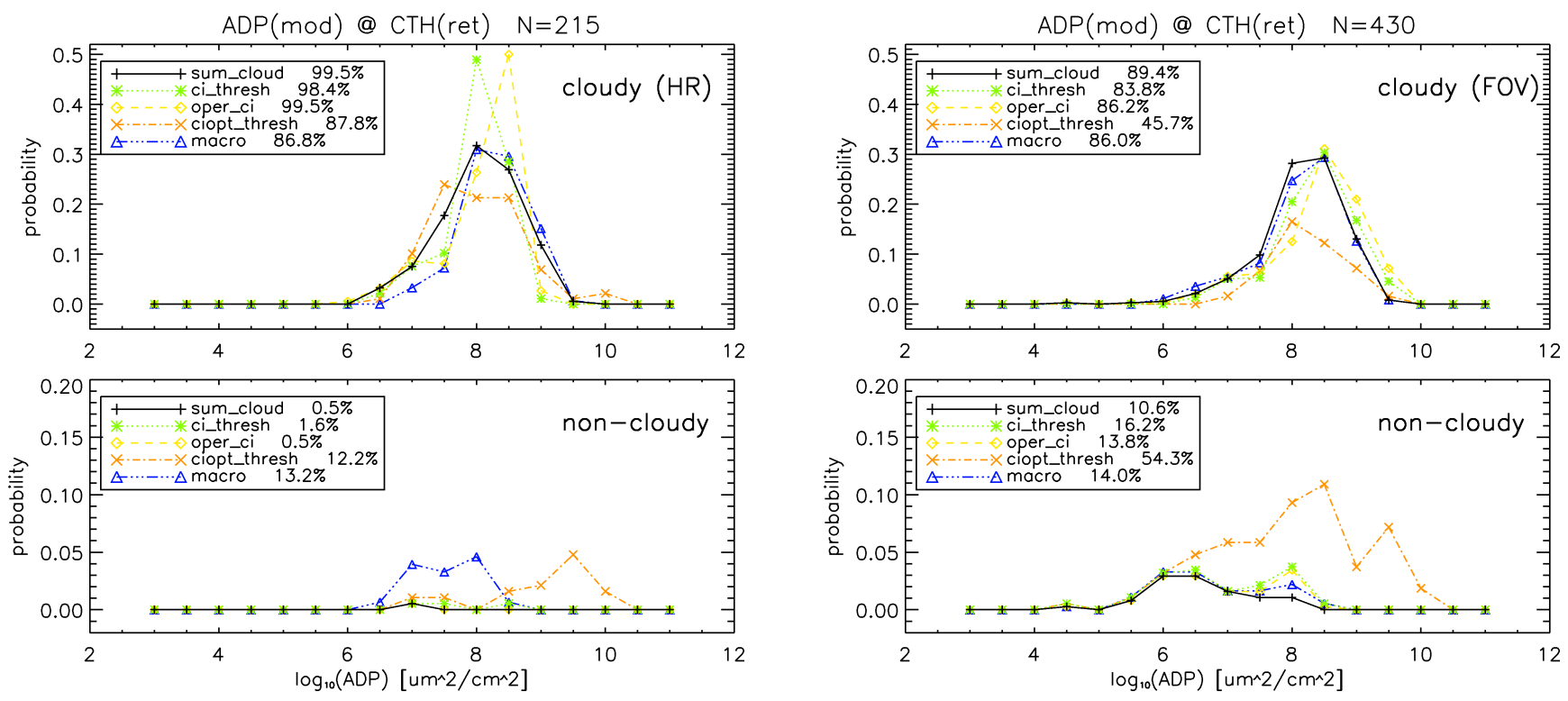

Fig. 9. Probability density functions (PDF) of all "true state" ADP values from the BTR input data (Scenarios 1-3) at the retrieved $\mathrm{CTH}$ of the various detection methods (top) in comparison with the PDF of the maximum "true state" ADP in the profiles where the detection methods retrieved non-cloudy conditions (bottom). Both analyses were carried out for the high-resolution (HR) model fields. Total percentages of detected and non-detected clouds for each method are presented in the figure legends.

location for HR (Fig. 9) and MIPAS resolution (Fig. 10). The statistics are performed together for Scenarios 1, 2 and 3 . The results show that all the methods are able to detect ADP values down to $10^{7} \mu \mathrm{m}^{2} \mathrm{~cm}^{-2}$. The maxima of most of the probability density functions (PDFs) are around $\log _{10}($ ADP $)=8$. Values of $\log _{10}($ ADP $)<6$ are definitively not detectable in the HR nor in the BTR with MIPAS resolution. In the HR case, almost all the potentially cloudy profiles are detected, e.g. up to $99.5 \%$ of all true state cloudy profiles $(\mathrm{ADP}>0)$ for the combined SUM_CLOUD detection. In the statistics for the MIPAS FOV resolution, the CIOPT_THRESH shows a significant weakness (only $<50 \%$ of the cloudy profiles are detected), where all other methods show good results with a success in detection of $85 \%$ to $90 \%$. The figures also show the PDF for the maximum ADP in the profile where the retrieval predicts non-cloudy conditions throughout the full profile (bottom diagram). The results give some evidence that modelled clouds with maximum ADP of $10^{7} \mu \mathrm{m}^{2} \mathrm{~cm}^{-2}$ are even difficult to detect with a combined detection analysis such as the SUM_CLOUD parameter (black line in the FOV case). The CIOPT_THRESH method misses more than $20 \%$ of the cloudy profiles even for relatively large $\operatorname{ADP}\left(>10^{8} \mu \mathrm{m}^{2} \mathrm{~cm}^{-2}\right)$, which is not that large in the HR case.

In summary, a detection threshold $\mathrm{ADP}_{\text {thres }}$ of $10^{7} \mu \mathrm{m}^{2} \mathrm{~cm}^{-2}$ is a good estimate for current cloud pro-

Fig. 10. Same as Fig. 9, but now for the retrievals of the two different MIPAS field-of-view convolutions applied to the modelled radiance fields (FOV), see also Sect. 4.2.

cessing. Better sensitivity will be difficult to achieve with the current methods. The optically thinnest parts of the clouds are in the region where the LOS hits an area with IWC $>0$ for the first time in a profile. In the vertical direction this is the top and in horizontal direction the side edge of the cloud structure. In these top regions, "true state" ADP values of $10^{4}-10^{7} \mu \mathrm{m}^{2} \mathrm{~cm}^{-2}$ appear. Due to grid interpolation effects these values might be even smaller than in the original ECMWF fields. However, it is very likely that the data do not cover even optically thinner cirrus structures present in the real atmosphere but not resolved in the ECMWF fileds.

To make the ADP detection threshold more comparable to other sensors or model data it is helpful to estimate equivalent typical IWP and IWC. By Eq. (5) the $\mathrm{ADP}_{\text {thres }}$ of $10^{7} \mu \mathrm{m}^{2} \mathrm{~cm}^{-2}$ can be transformed into a limb-integrated IWP $/ R_{\text {eff }}$ of $0.03 \mathrm{~g} \mathrm{~m}^{-2} \mu \mathrm{m}$. If one assumes a typical effective radius for optically thin cirrus clouds of $10 \mu \mathrm{m}$, this results in an equivalent limb IWP of $0.3 \mathrm{~g} \mathrm{~m}^{-2}$. For a horizontally extended cloud layer of $300 \mathrm{~km}$ or a very small extent of $3 \mathrm{~km}$ along the LOS, this results in an IWC of $\sim 10^{-7} \mathrm{~g} \mathrm{~m}^{-3}$ and $\sim 10^{-5} \mathrm{~g} \mathrm{~m}^{-3}$, respectively. These values are in the typical range of IWC in-situ measurements in subvisual cirrus clouds. For example McFarquhar et al. (2000) measured IWC values from $10^{-4} \mathrm{~g} \mathrm{~m}^{-3}-10^{-6} \mathrm{~g} \mathrm{~m}^{-3}$, similar to Lawson et al. (2008) with values between $5 \times 10^{-4} \mathrm{~g} \mathrm{~m}^{-3}$ $10^{-6} \mathrm{~g} \mathrm{~m}^{-3}$. Davis et al. (2010) found in laminar SVC structures IWC values of significantly less than $10^{-5} \mathrm{~g} \mathrm{~m}^{-3}$ over a vertical extent of a few hundred meters of the cloud. The authors showed that CALIPSO would be missing $\sim 2 / 3$ of this type of ultrathin cirrus clouds. 

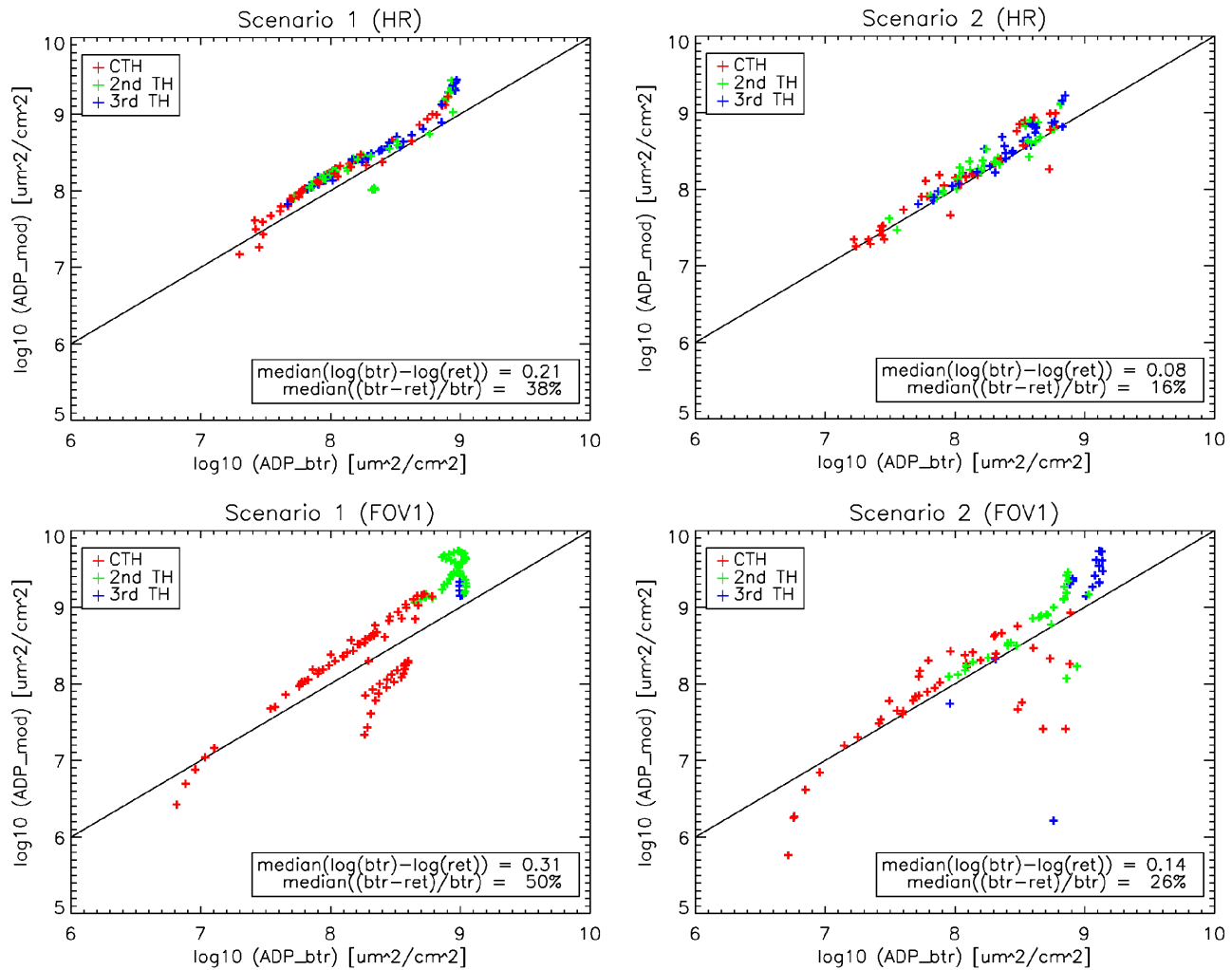

Fig. 11. Retrieved ADP versus "true state" ADP values at the detected CTH in blind test data fields for Scenario 1 and 2 (left/right). Top figures show the high-resolution (HR) and the bottom figures the FOV convolution results.

The estimated low IWC detection thresholds for MIPclouds are highlighting, on the one hand, the high sensitivity of the detection methods applied and, on the other hand, the exceptional sensitivity of IR limb sounding in general for the measurement of optically thin and/or vertically and horizontally small cloud structures. The long optical path through the clouds indicates the robust detection of ultrathin SVC (optical depths between $10^{-5}$ and $10^{-3}$, Davis et al., 2010) which are difficult to measure even with spaceborne lidars.

More detailed comparisons with in-situ and CALIPSO measurements are a priority for the ongoing completion of the MIPclouds processing. The long data record (20022011) can provide complementary and additional information for climatologic datasets of the global occurrence of (ultrathin) cirrus clouds in the tropopause region. This information is essential for the evaluation of climate model results.

\subsection{Error estimate of retrieved ADP}

A comparison of the "true state" ADP values computed from the input parameter fields for the radiative transfer calculation $\left(\mathrm{ADP}_{\mathrm{mod}}\right)$ and the results of the ADP blind test retrieval $\left(\mathrm{ADP}_{b t r}\right)$ is used to estimate the error in the ADP retrieval (introduced in Sect. 3). Figure 11 shows correlation diagrams for the retrieved $\mathrm{ADP}_{b t r}$ versus the true state $\mathrm{ADP}_{\text {mod }}$ for Scenarios 1 and 2 for the high-resolution $0.5 \mathrm{~km}$ and the
FOV1 blind test retrieval. In the retrieval processing, ADP is only generated for the $\mathrm{CTH}$ and two altitude levels below. Generally, all scenarios show a quite compact correlation and the differences are smaller than $50 \%$ for most of the comparison. Only for some optically thicker events (large ADP) do the errors become larger and here especially for the two tangent heights below the cloud top, where horizontal cloud inhomogeneities might produce larger errors in the simple fitting approach of the ADP retrieval.

There is an obvious tendency to a low bias in the retrieved ADP. A median of $\sim 30 \%$ for the relative differences is found over all scenarios for the MIPAS FOV runs, where the tropical blind tests show a systematically smaller offset $(20 \%$ and $50 \%$ for the mid-latitude scenario 1). The low bias is quite constant in $\log _{10}$ (ADP) for each specific case and results in median values of 0.1 (tropics) up to 0.3 (mid-lat). In addition, the high resolution blind tests show generally smaller biases than the MIPAS FOV runs. This is an indication that the modelled $\mathrm{CI}_{\mathrm{A}}$ versus ADP used for the ADP retrieval causes larger errors if a broad FOV comes into play.

\section{Validation of cloud detection}

Various spaceborne, airborne and ground-based measurements were investigated with respect to potential 
coincidences with the MIPAS instrument for the time period September 2002 to March 2004. Three types of validation methods are applied to the processor output parameters, depending on the dataset or parameter of interest:

1. Validation on the basis of coincident measurements in a certain miss-time and miss-distance window.

2. Statistical comparison of parameters based on temporal and spatial means.

3. Blind test retrievals based on modelled spectra of realistic cloud scenarios (Sect. 4).

In the following sections, attention is focused on the validation of cloud detection and corresponding parameters such as cloud occurrence frequencies (COF) or high cloud amount (HCA). Other parameters (CTH, CTT, CEX) have already been investigated in detail by Hurley et al. (2011) or are still under investigation and will be published at a later stage (e.g. classification and $R_{\text {eff }}$ ).

\subsection{Comparisons with the SAGE II dataset}

\subsubsection{SAGE II instrument and data}

The Stratospheric Aerosol and Gas Experiment II (SAGE II) is a solar occultation instrument (McCormick, 1987) and is especially suited for the validation of the MIPAS cloud detection. The instrument measures in the limb direction, which counteracts basic problems due to different viewing geometries, and has the sensitivity to detect subvisible cirrus clouds (Wang et al., 1996). These are the optically thinnest clouds and they are usually invisible for nadir or geostationary sounders. The SAGE II instrument has a much better vertical resolution than MIPAS $(\mathrm{FOV}=0.5 \mathrm{~km})$ and is able to detect clouds and aerosols down to extinctions $(\varepsilon)$ of $10^{-6} \mathrm{~km}^{-1}$ at visible wavelengths. By means of a twowavelength approach it is possible to differentiate between background aerosol and SVC. According to the analyses of Wang et al. (1994), SAGE II can detect SVC down to extinctions of $2 \times 10^{-4} \mathrm{~km}^{-1}$ at a wavelength of around $0.7 \mu \mathrm{m}$, which is in line with the lower bound of the typically applied cirrus classification by Sassen and Cho (1992). Generally, SAGE II is able to detect SVC in the extinction range $3 \times 10^{-4}-3 \times 10^{-2} \mathrm{~km}^{-1}$ for the SAGE II $1.02 \mu \mathrm{m}$ channel (Wang et al., 1994). We analysed the height-resolved cloud flag in the SAGE II version 6 data (SAGE, 2011). Due to the use of the occultation technique (typically 30 sunrise and sunset measurements per day), the number of coincident measurements is limited. In the period of interest 9/2002 to $3 / 2004$, the SAGE II measurement sampling was reduced to only 15 profiles per day. Due to the limited number of coincidences, the following analyses also used climatological means of the global distributions of subvisible cloud occurrence above specific altitude levels for the time period $12 / 1998$ to $11 / 2004$.

\subsubsection{Comparison of the mean CTH of MIPAS detection methods}

In a first step of the validation, the differences in sensitivity between each detection method were investigated using the SAGE II SVC data for reference. The systematic differences between the zonal mean CTH of each method are illustrated in Fig. 12. CTH is defined by the tangent height of the first cloudy spectrum detected in the MIPAS or SAGE II vertical top-down scan. The computation of zonal means is restricted to altitudes above $6 \mathrm{~km}$ where all methods are applicable. For the colour ratio methods, we selected only the band A cloud index for OPER_CI, CIOPT_THRESH, and CI_THRESH (defined for $\mathrm{CI}_{\mathrm{A}}$ only) as well as the complementary methods SVD and macro physical retrieval, which are based on the multi-wavelength approach. The zonal means can give an indication of the detection sensitivity of the applied methods. However, large values can also suggest erroneous detection events, where, for example, the CI threshold value has an overlap with CI values typical of cloud-free conditions.

Overall, the highest mean cloud top heights were found in the tropics and for winter in the Antarctic polar vortex, where PSC are detected up to altitudes of $28 \mathrm{~km}$. Differences between the methods are more or less constant for all latitudes and up to a maximum of $3 \mathrm{~km}$, which is equivalent to one altitude step in the MIPAS scan. Differences larger than $3 \mathrm{~km}$ are linked to the PSC season (May - September), where MACRO and CIOPT_THRESH show the highest mean CTH and consequently the highest sensitivity. For all seasons, the detection methods show significant and systematic differences. The optimised CI-threshold method produces the highest mean CTHs followed by the macro retrieval and the CI_THRESH method. SVD and OPER_CI show very similar mean CTHs and consequently quite similar detection sensitivity.

The large mean CTH for CIOPT_THRESH are caused by problems in detection for lower altitudes $(<9 \mathrm{~km})$ where the selected threshold $<1$ (see Fig. 3) for the tropical and northern mid-latitudes seems to be too conservative for the detection of any cloud at all. An underestimate of cloud occurrence at these lower altitudes results in a larger mean CTH than for the other methods, also in comparison with the climatological mean of SAGE II. The same problem occurs for all SAGE II comparisons in general, due to the fact that the SAGE II climatology does not include opaque clouds following the definition of Wang et al. (2001). A differentiation of opaque and subvisible cirrus is so far not implemented in the MIPAS processing. This would be achievable by the extraction of an ADP threshold in the CI-ADP correlation (Fig. 6). However, this threshold would be altitude dependent and not comparable with the SAGE II definition of opaque conditions. The inclusion of optically thick clouds in the IR measurements can cause biases when comparing both data sets, especially at lower altitudes. 

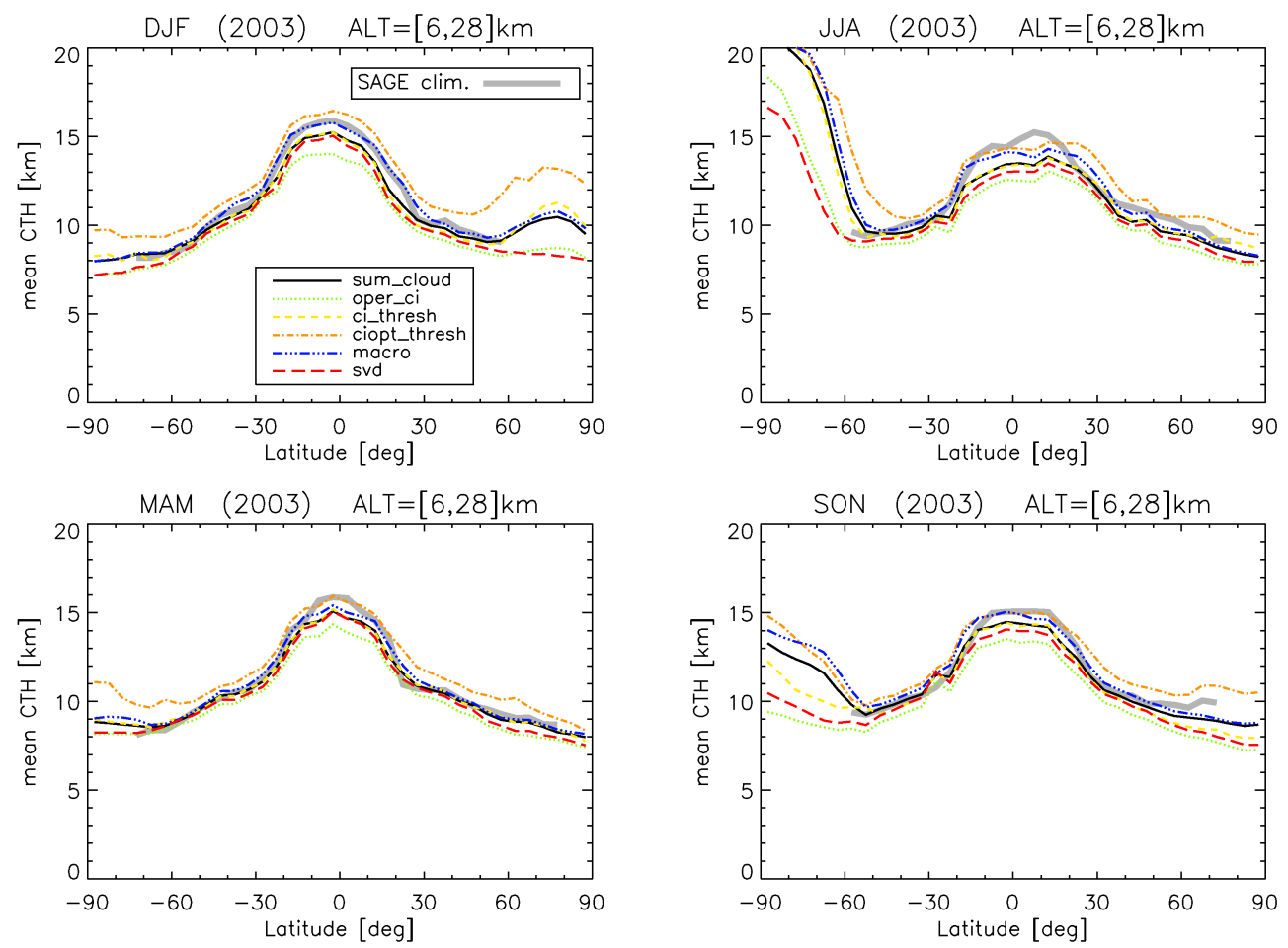

Fig. 12. The zonal mean CTH for various detection methods above $4 \mathrm{~km}$ altitude for spring, summer, autumn and winter seasons in the 2002 (Dec) to 2004 (January-November) time period together with the corresponding SAGE II climatology distribution (for details see text).

The parameter SUM_CLOUD in Fig. 12 refers to the summary CTH information, the combination of all detection methods of the cloud processor. As introduced in Sect. 3.1.4, for the current version (V1.6) of the processor, the SUM_CLOUD information is usually dominated by the CTH information of the macro retrieval. If the macro result is not available then weighted information of a selected number of detection methods is used. Consequently SUM_CLOUD and macro retrieval mean CTHs differ only marginally.

The standard deviation $(\sigma)$ of the zonal mean CTH is illustrated in Fig. 13. Large variability occurs typically at latitudes where stratospheric and tropospheric clouds can be observed in the same season (winter) and with similar occurrence frequency, for example for JJA inside the southern polar vortex. Usually these regions are not covered by the SAGE II dataset. The detection methods SVD and CIOPT_THRESH show the largest $\sigma$-values. The strong enhancement for the CIOPT_THRESH method compared to all other methods at relatively low latitudes for the polar winter season at $50^{\circ} \mathrm{N}$ and $40^{\circ} \mathrm{S}$, respectively, is an indicator of the slightly oversensitive threshold value for this specific latitude and altitude region, which might create artefacts of even slightly overestimated CTHs in some of the profiles.

The CTH standard deviation for SAGE II and MIPAS shows a very good correspondence in absolute values, with minima of $1.5 \mathrm{~km}$ and maxima of around $4.5 \mathrm{~km}$, also for the latitudinal distribution, with local maxima at the tropical jet regions $\left( \pm 30^{\circ}\right)$ and minima at mid- to high-latitudes and a local minimum at the equator. The overall good correspondence highlights the fact that both instruments observe primarily the same kind of clouds, namely SVC.

\subsubsection{Comparison of horizontal cloud occurrence frequencies}

The analysis for subvisible cirrus cloud occurrence frequencies (COF) in the SAGE II data is described in detail in Wang et al. (1996) and for comparisons with other limb sounders in Spang et al. (2003). Here, we apply a slightly different approach to consider in a more robust form the different fields of view $(0.5 \mathrm{~km} / 3 \mathrm{~km})$ and vertical sampling $(0.5 \mathrm{~km} / 3 \mathrm{~km})$ of the SAGE II and MIPAS instruments. Instead of measuring COF within a specific altitude box, the COF is computed above a certain grid altitude $h_{i g}$. The instrument-specific FOV is considered by subtracting the maximum uncertainty where the cloud top is located in the field of view from the tangent height $\left(h_{\mathrm{io}}=\mathrm{TH}-\mathrm{FOV} / 2\right.$, but not for the macro retrieval, where the FOV is already considered). In addition, only the CTH information is considered for the COF, because for information on cloudiness for the layers below the CTH this is not unambiguously assured. That is to say, the radiances measured at tangent heights below the CTH are dominated by the cloud top radiances, resulting in a kind of shadowing effect, which can bias the statistics for both 

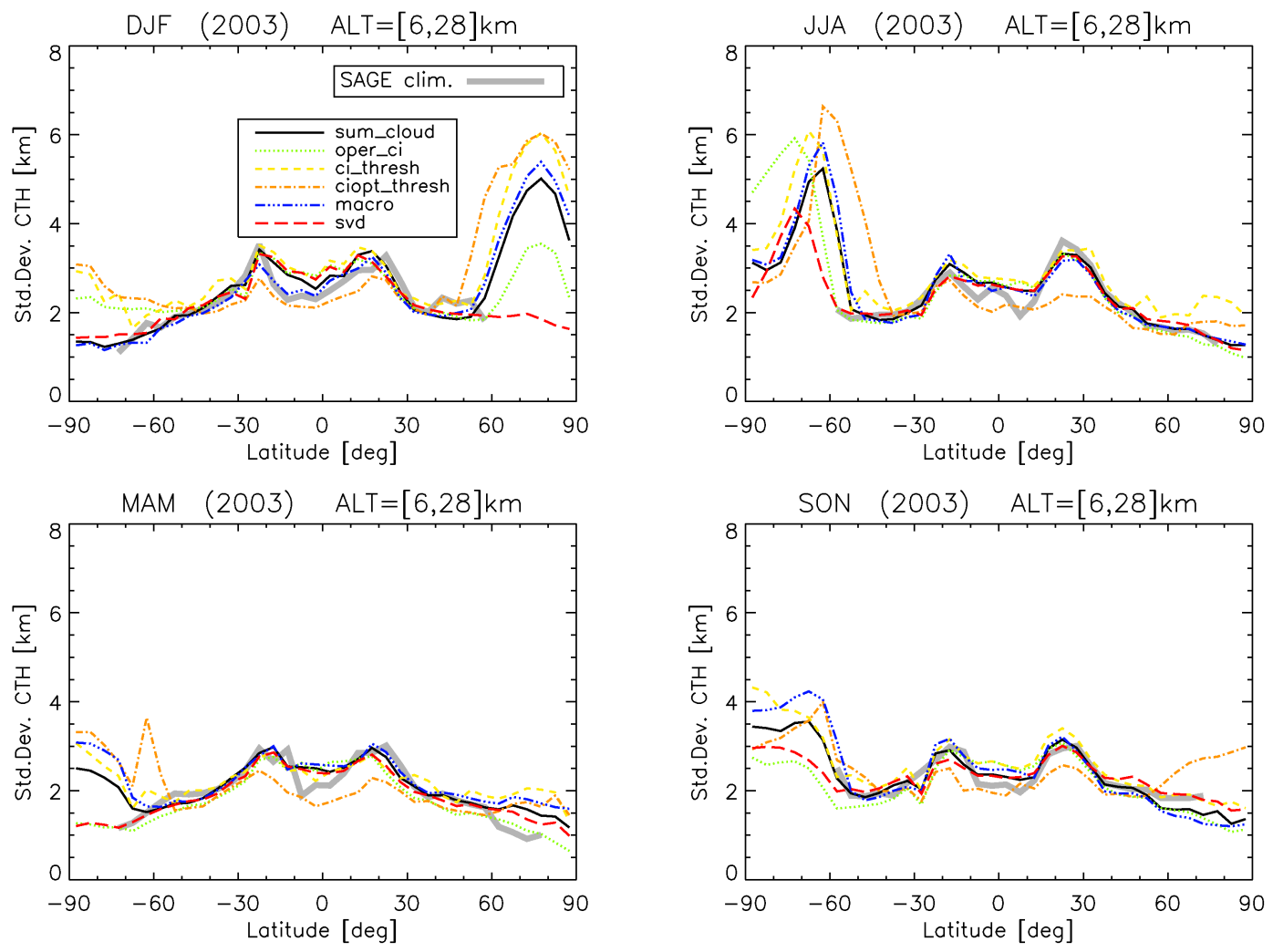

Fig. 13. The standard deviation of the zonal mean CTH for various detection methods above $4 \mathrm{~km}$ altitude for the spring, summer, autumn and winter seasons in the 2002 (December) to 2004 (January-November) time period.

instruments. The MIPAS and SAGE II datasets were analysed in an identical way. CTHs were used for the computation of cloud occurrence frequencies $f_{\mathrm{c}}(\mathrm{COF})$ above a certain altitude. A $1 \mathrm{~km} \times 10^{\circ} \times 20^{\circ}$ grid for altitude, latitude and longitude was defined and the MIPAS parameter SUM_CLOUD is usually used in the following comparisons. A minimum of five observations per grid box was found necessary for consideration in the analysis.

The comparison of the resulting cloud occurrences is illustrated in Fig. 14 for $15 \mathrm{~km}$ altitude for the December/January/February NH winter season (DJF) and June/July/August NH summer season (JJA). The horizontal pattern is very similar between MIPAS and SAGE II. However, discrepancies at specific regions are obvious as well. The pattern shows the expected maxima in the warm pool regions over the Micronesia-West-Pacific region, Central Africa and Central America. Also obvious is the consistent slight shift in the COF distribution between $\mathrm{NH}$ summer and winter conditions in line with the drift of the intertropical convergence zone (ITCZ) for both datasets. For the DJF season, the peak COF values of MIPAS are significantly larger than the SAGE II values. Differences of up to $20-30 \%$ can be observed. However, for JJA the systematic difference in the tropics is partly compensated, and the differences are more randomly distributed, most likely caused by annual variability.

At mid-latitudes, the $\mathrm{COF}$ values are strongly reduced at this altitude. Around $50^{\circ} \mathrm{N}$, SAGE II shows a few percentage points more in COF than MIPAS, but in other regions the differences are usually around $\pm 5-10 \%$, and no systematic offset between the instruments is observed.

Generally, differences might be affected by the natural annual variability in COF, when comparing a specific year with a climatology of 6 yr. El Nino-La Nina effects in the longitudinal cloud distribution need to be considered in more detail to quantify and understand the differences. For example, the 1998-2004 period includes only one El Nino event and was classified as a moderate El Nino, but the main signal of this event was just between October 2002 and January 2003 (e.g. see Oceanic Nino Index (ONI) at the Climate Prediction Centre-NOAA website). This is highlighted in the MIPAS data by the enhanced COF values in the east Pacific and the extension of enhanced COF values to the south-east of the Pacific in the DJF season, which is typical of El Nino conditions (e.g. Spang et al., 2002; Wang et al., 1996).

The strong signals of Arctic and Antarctic clouds (mainly PSCs) in the MIPAS data are not expected in the SAGE II data. Due to the analysis of the SVC flag in the SAGE II data, the results are not sensitive to PSCs, but discrepancies 



Fig. 14. MIPAS (top) parameter SUM_CLOUD for DJF and JJA 2002/2003 and SAGE II (middle) SVC climatology of occurrence frequencies and the corresponding differences of MIPAS-SAGE II (bottom panels) for altitudes above $15 \mathrm{~km}$. Overlaid contour lines run from 1 , 5 , $10,20 \ldots$ to $90 \%$.

are also affected by the limited geographical coverage of SAGE II measurements in these regions for the specific seasons.

\subsubsection{Zonal mean cloud occurrences}

The analysis of the zonal mean COF might give more insights into systematic differences between the two datasets and might also show some strengths and weaknesses of specific MIPAS detection methods. Figures 15 and 16 present the COF distribution of the macro retrieval, the OPER_CI and SVD methods in comparison to SAGE II, again for the DJF and JJA season. OPER_CI and SVD show the effects of the relatively broad FOV of MIPAS by the step-like changes in contour lines. The macro retrieval runs clear of the FOV effect due to specific handling of the FOV in the retrieval (Hurley et al., 2011), and shows for both seasons a good correspondence in the COF distribution with SAGE II. The macro results show cloud occurrences on a $1 \%$ level in the tropics up the $20 \mathrm{~km}$ and $21 \mathrm{~km}$ level, which is significantly higher $(1-3 \mathrm{~km})$ than for SAGE II and the two other MIPAS methods. The observation of clouds above $20 \mathrm{~km}$ seems quite high. This is clearly in the stratosphere and due to the increasing temperatures and low water vapour mixing ratios (typically 2-4 ppmv) the formation of cirrus clouds becomes very unlikely. So far, it is not found in other remote sensing or in situ datasets. The cloud events in the stratosphere are potentially artefacts of the macro retrieval related to vertical smoothing effects caused by the coarse FOV and sampling grid $(3 \mathrm{~km})$. Over-sampling used in the MIPAS measurement since the end of 2004 ( $2 \mathrm{~km}$ steps) might help to reduce this effect.

Generally, in the tropics SAGE II and all MIPAS methods show a consistent decrease between DFJ and JJA for 

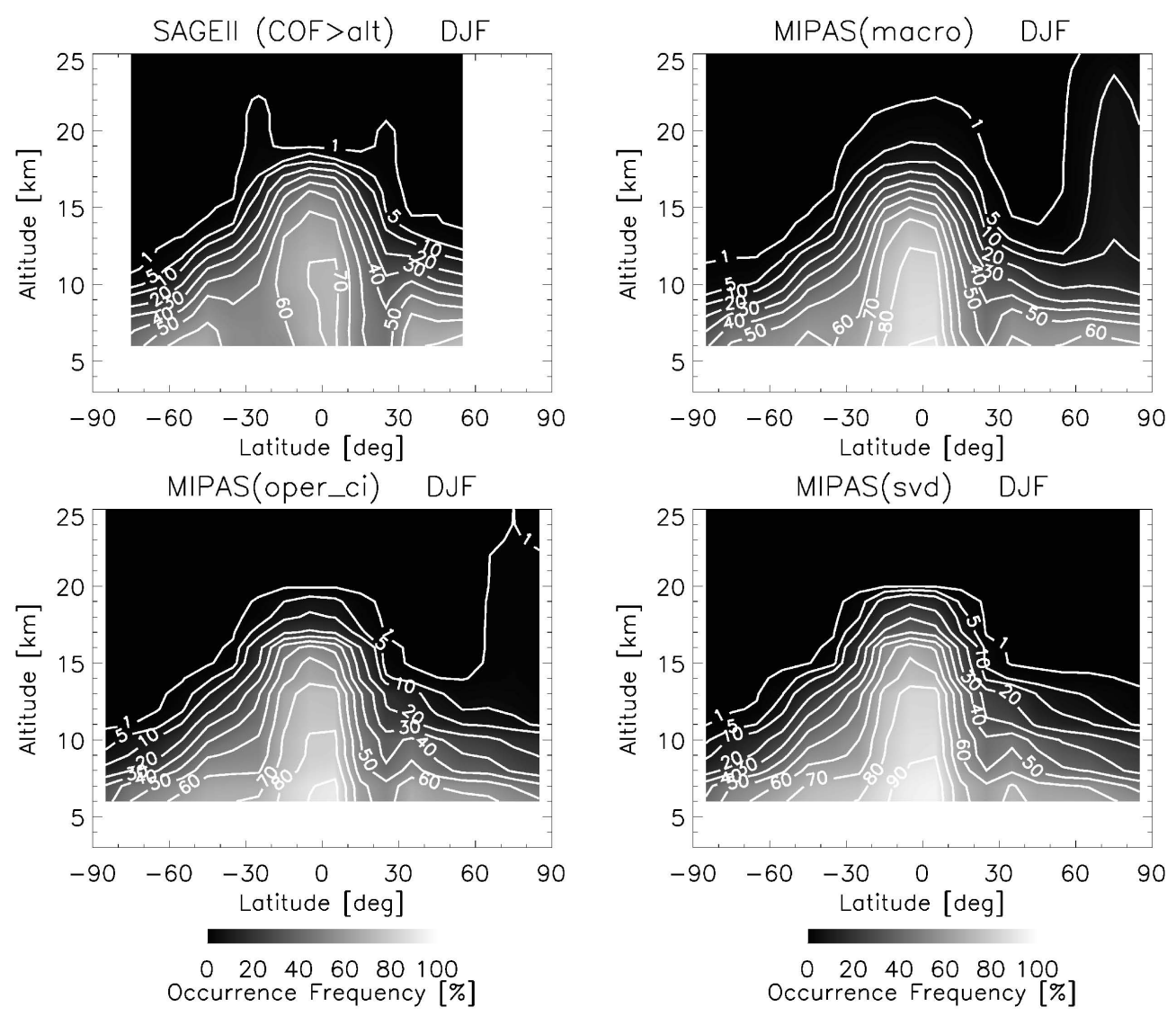

Fig. 15. Zonal mean cloud occurrence frequencies (COF) above a certain altitude for the MIPAS detection methods MACRO, OPER_CI and SVD in comparison to SAGE II (top left) for the Dec-Jan-Feb (DJF) season 2002/2003 and the climatology time period of December 1998-November 2004, respectively.

CTH occurrences at higher altitudes in the tropics, whereby mid-latitudes indicate the opposite effect for the winter hemisphere. All zonal means show minima in COF around $30^{\circ}$ south and north, and local maxima around $45-50^{\circ} \mathrm{N} / \mathrm{S}$. These local extremes are more pronounced in the SAGE II data. The former are affected by the different handling in the statistics of clouds which are opaque for SAGE II. These clouds are not included in SAGE II but are included in the MIPAS statistics, because they cannot be distinguished from optically thinner clouds in the MIPAS measurements. This might also be the reason that the MIPAS zonal means do not show any local maximum in the tropical upper troposphere between 9-12 km whereas SAGE II does. Instead they always have an increasing $\mathrm{COF}$ with decreasing altitude at all latitudes.

The observation of PSCs is not possible with the SAGE II cloud information flag used here, but the comparison between the methods for MIPAS indicates the higher sensitivity for PSC detection for the macro retrieval and the limitations of the SVD method for detecting clouds above $21 \mathrm{~km}$, especially in the winter SH polar vortex where the PSC occurrence frequency reaches its maximum. Finally, the overall good correspondence between MIPAS and SAGE II in the COF analysis is in line with a comparison between SAGE II and the CRISTA infrared limb sounding instrument (Spang et al., 2002).

\subsubsection{SAGE II - MIPAS coincidences}

In the period September 2002 to March 2004, around 1600 MIPAS - SAGE II coincidences were found for a misstime/miss-distance criterion of 4 hours and $400 \mathrm{~km}$, respectively. The tropics $\left(30^{\circ} \mathrm{S}-30^{\circ} \mathrm{N}\right)$ include only 134 events and no coincidences were found for high southern latitudes $\left(>60^{\circ} \mathrm{S}\right)$ where coincidences are dominated by PSC observations in the MIPAS data, which are not included in the SAGE II cloud flag. Figure 17 summarises the mean difference in CTH between MIPAS and SAGE II for $3 \mathrm{~km}$ altitude bins. Each MIPAS detection method is compared to SAGE II, only results where both instruments show a CTH in the profile (cloudy-cloudy) are included in the statistics. Finally, the tropics did not show sufficient count statistics of cloudycloudy coincidences (only 28 events) for an altitude-resolved analysis and the comparison in the polar region of the southern hemisphere was not meaningful due to the shadowing 

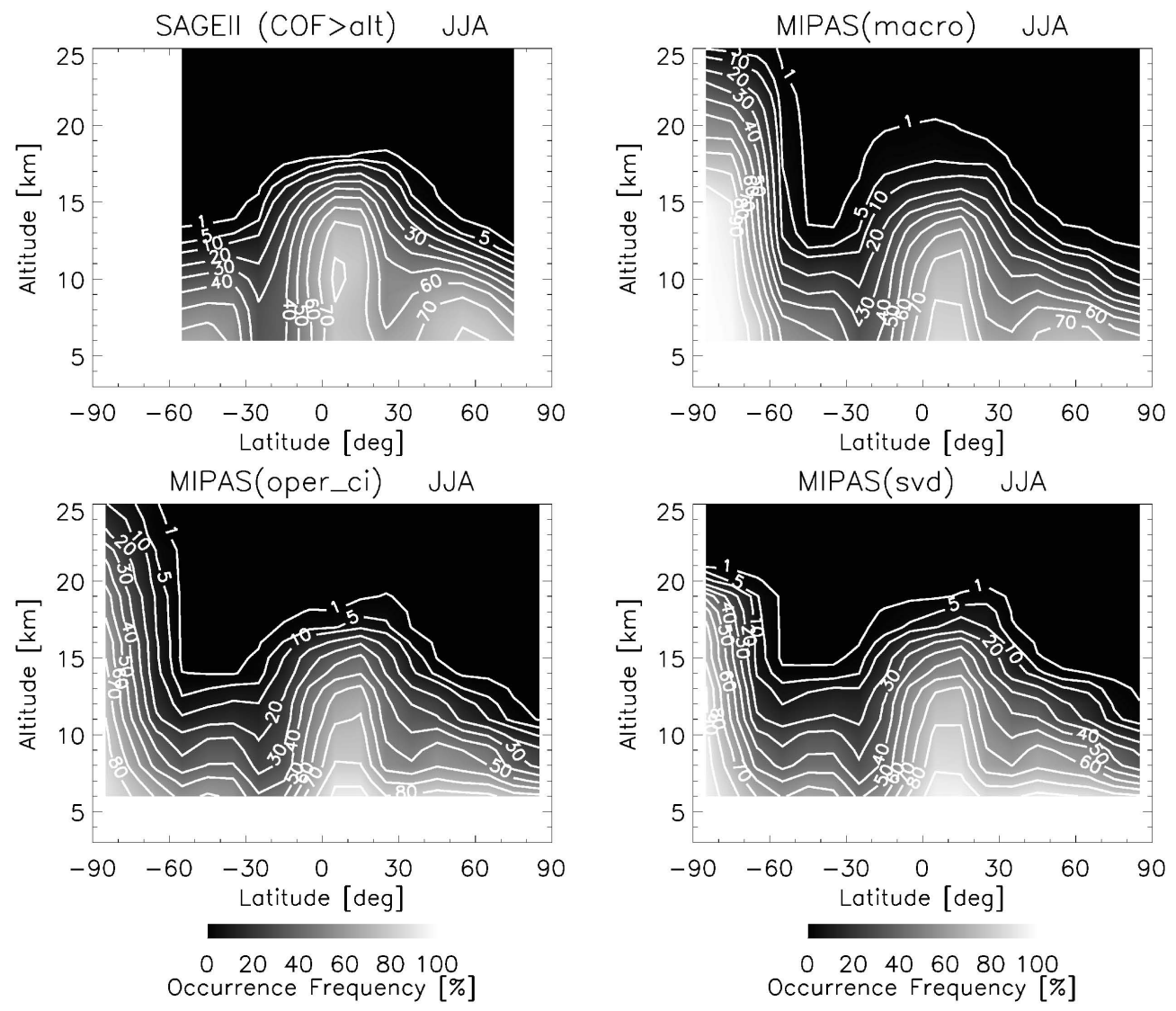

Fig. 16. Zonal mean cloud occurrence frequencies above a certain altitude for the MACRO, OPER_CI and SVD detection methods of MIPAS in comparison to SAGE II (top left) for the Jun-July-Aug (JJA) season 2002/2003 and the climatology time period of December 1998-November 2004, respectively.

effect by PSC in the MIPAS measurements. The results for the three remaining latitude bands give a consistent picture for all MIPAS detection methods. MIPAS CTHs around the tropopause (top two levels) show a very small difference to SAGE II $( \pm 1 \mathrm{~km})$, with a tendency to higher CTHs for MIPAS for the top altitudes. This indicates slightly higher detection sensitivity for MIPAS in this region, which is also highlighted in the summary statistics of Table 4, where usually the number of MIPAS cloud events with no SAGE cloud detection is significantly larger for all latitude bands than vice versa and these differences are mainly caused by high clouds (not shown). At the lower two altitude levels, the difference between MIPAS and SAGE II becomes significantly negative and increases with decreasing altitude from $1-2$ to $3-5 \mathrm{~km}$, depending on the detection method. MIPAS seems to lose sensitivity compared to SAGE II when penetrating into the troposphere.

Table 4 summarises the coincidence statistics. All combinations of coincidences are accounted for: cloudy to noncloudy for SAGE II and MIPAS, respectively, both cloudy, and both non-cloudy. Percentages are given with respect to the total number of coincidence events (bottom row).
For high northern latitudes the agreement is excellent, only $12 \%$ and $13 \%$ of the coincident profiles are flagged as cloudy when the other instrument detects no cloud. At low latitudes there is less agreement. Yet the number of coincidences is also significantly smaller than at high and midlatitudes and consequently the statistical significance is reduced.

Coincidences at high southern latitudes are mainly observed during polar winter and are dominated by high occurrence rates of PSC observations in the MIPAS measurements. The detection of PSCs is not covered by the SAGE II detection SVC flag. Consequently, the discrepancies for the cloud/no-cloud events are not meaningful. But there is a significant correspondence for non-cloudy conditions between the instruments. No clouds are detected by SAGE II when MIPAS predicts non-cloudy conditions for the coincidence.

In the tropics, MIPAS detects in $39 \%$ of the coincidences a cloud where SAGE II seems cloud-free, whilst for $8 \%$ of the profiles SAGE II detected a cloud for cloud-free conditions with MIPAS. The imbalance is basically caused by MIPAS detections with CTHs above $15 \mathrm{~km}$. This is indicating a higher detection sensitivity for MIPAS than SAGE II 
Table 4. Coincidence statistics between SAGE II and MIPAS.

\begin{tabular}{lccccc}
\hline Latitude & $90^{\circ} \mathrm{S}-60^{\circ} \mathrm{S}$ & $60^{\circ} \mathrm{S}-30^{\circ} \mathrm{S}$ & $30^{\circ} \mathrm{S}-30^{\circ} \mathrm{N}$ & $30^{\circ} \mathrm{N}-60^{\circ} \mathrm{N}$ & $60^{\circ} \mathrm{N}-90^{\circ} \mathrm{N}$ \\
\hline SAGE II no-cld* & $65 \%$ & $25 \%$ & $39 \%$ & $27 \%$ & $13 \%$ \\
MIPAS no-cld* & $0^{* *}$ & $14 \%$ & $8 \%$ & $11 \%$ & $12 \%$ \\
both non-cloudy* & $35 \%$ & $21 \%$ & $32 \%$ & $14 \%$ & $5 \%$ \\
both cloudy* & $0^{* *}$ & $39 \%$ & $21 \%$ & $48 \%$ & $70 \%$ \\
No. of events & 283 & 247 & 134 & 389 & 590 \\
\hline
\end{tabular}

* All percentages are given for the MIPAS summary cloud detection parameter SUM_CLOUD

** MIPAS observations are dominated by PSCs, which are not detectable with the SAGE II SVC flag.
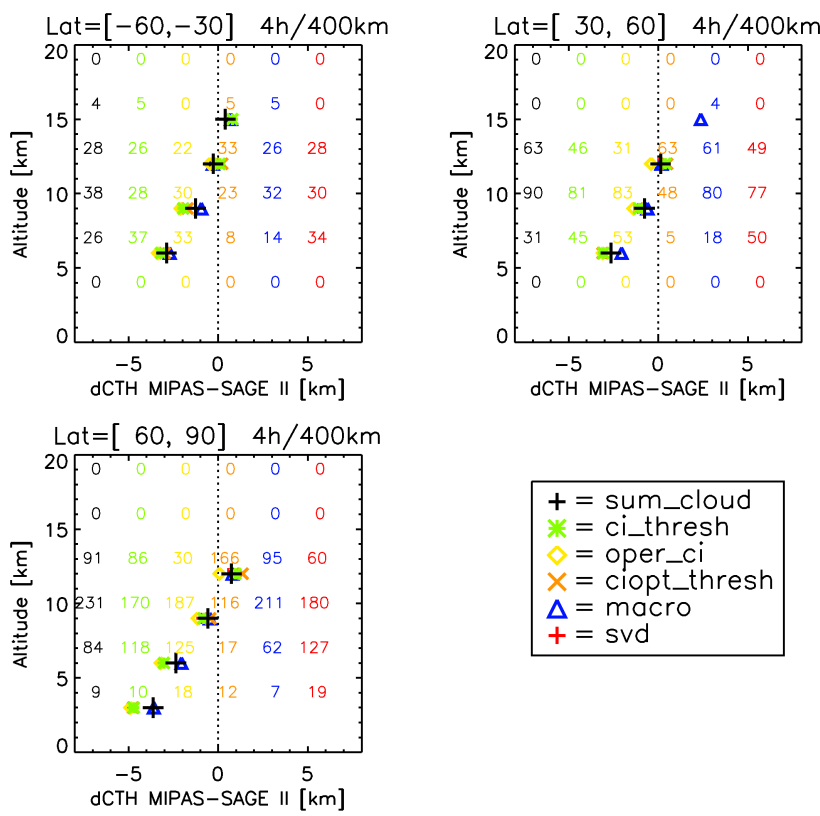

Fig. 17. Mean difference in CTH between MIPAS and SAGE II for coincident cloudy profile measurements between October 2002 and March 2004 on a $3 \mathrm{~km}$ altitude grid and three latitude bins $\left(60^{\circ} \mathrm{S}-\right.$ $30^{\circ} \mathrm{S}, 30^{\circ} \mathrm{N}-60^{\circ} \mathrm{N}$, and $60^{\circ} \mathrm{N}-90^{\circ} \mathrm{N}$ ). Coloured symbols indicate the different MIPAS detection methods and the coloured numbers represent the counts of CTHs for MIPAS for the corresponding altitude bin and detection method.

for cirrus clouds around the tropical tropopause (see also Sect. 5.1.4).

At mid-latitudes the percentages of in-conclusive results are reduced, but there are still significantly higher detection rates for MIPAS. In this case the events are not caused by detections around the tropopause $(\sim 12 \mathrm{~km})$ but due to detections at lower altitudes (6 and $9 \mathrm{~km})$. In this region the analysis is biased by missing opaque clouds in the SAGE II statistic. The amount of both-cloudy coincidences is higher than in the tropics and indicates generally better agreement for mid-latitudes.

Although both SAGE II and MIPAS use the limb technique, the satellite orbit for the occultation measurements results in a quite different viewing direction than for the emission instrument when probing the same air mass. This fact, together with the relatively large coincidence criteria $(400 \mathrm{~km} / 4 \mathrm{~h})$, may produce misleading results (reduced number of both-cloudy coincidences) especially in the midtroposphere where the horizontal cloud scales are smaller. These restrictions seem to affect especially the mid- and tropical latitude analysis. An unbalance in the amount of inconclusive (cloudy/non-cloudy) coincidences between the instruments is always an indication for differences in the detection sensitivity or a hypersensitivity of a specific detection method. This becomes obvious for MIPAS in the midlatitudes and tropopause region of the tropics.

\subsection{Comparison with the GLAS instrument}

\subsubsection{GLAS instrument and data}

One of the few techniques available to obtain continuous daily global coverage of subvisible/ultra-thin cirrus clouds and PSCs are space-borne lidars. Launched in early 2003, the Geoscience Laser Altimeter System (GLAS) on the Ice, Cloud and Land Elevation Satellite was the first polar orbiting satellite lidar and is intended for comprehensive earth science applications covering surface altimetry for ice sheets and vegetation and atmospheric profiling (Spinhirne et al., 2005). The instrument design included high-performance observations of the distribution and optical scattering cross sections of atmospheric clouds and aerosol. The backscatter lidar operated at two wavelengths, 532 and $1064 \mathrm{~nm}$, whereby only the $532 \mathrm{~nm}$ measurements are used in the following analyses. With a measurement frequency of $40 \mathrm{~Hz}$ the instrument achieved a horizontal resolution of $170 \mathrm{~m}$ and vertical resolution of $80 \mathrm{~m}$.

During the first phase of MIPAS observations (June 2002 to March 2004) GLAS recorded continuous data between 25 September and 18 November 2003. For the analysis of coincidences we use all available MIPAS and night-time GLAS data. We found that no coincidences exist for time differences below $2 \mathrm{~h}$ at some latitude bands. As a compromise between as-close-as-possible matches and sufficient data for statistical purposes, a maximum miss-time of $\Delta t=2 \mathrm{~h}$, and a maximum miss-distance in location of $\Delta d=200 \mathrm{~km}$ were selected. 


\subsubsection{How to compare nadir and limb viewing cloud top heights?}

When looking at the two measurement geometries of MIPAS and GLAS, limb and nadir, the question arises of how to compare the cloud detection results of two instruments primarily in terms of vertical and horizontal resolution. Two different approaches were applied: from each ensemble of matching GLAS profiles belonging to a single MIPAS limb scan, we (1) used the mean lidar cloud top height of only the cloudy samples or (2) the lidar cloud top height was assigned to the maximum of all cloud top heights of the sample. Global statistics on the mean differences at different altitudes showed that the second approach results in the most consistent comparison between the two instruments, which makes sense since MIPAS is most sensitive to the first and usually highest cloud fragment along the line of sight of the instrument. In addition, the miss-distance criterion of $200 \mathrm{~km}$, which is equivalent to a diameter of $400 \mathrm{~km}$, considers to some extent the limb path smearing effect along the LOS through the tangent height layer $(\sim 400 \mathrm{~km}$ for a vertical FOV of $3 \mathrm{~km}$ ). Consequently, we only present results for the lidar maximum CTH for the miss-time/miss-distance criteria. A similar slightly simplified approach is applied for the comparisons of MIPAS with horizontally high resolved IR/uv/vis nadir sounders, and this is described in Sect. 5.3.2.

\subsubsection{Height resolved coincidence analysis for GLAS}

Figure 18 shows a summary of the mean differences between the CTHs of the various MIPclouds detection methods and the lidar coincidences. As already mentioned in Sect. 5.1.3, the results for the lidar maximum CTH for the miss-time/miss-distance criteria are best suited for the comparison with MIPAS. For better visibility, the differences are binned within altitude bands of $3 \mathrm{~km}$ height. Numbers on the left inside the plots indicate the number of coincident sample pairs which fall into the respective altitude range for the SUM_CLOUD parameter results. The following discussion will concentrate on those altitude bins with a sufficient number of samples (i.e. $>20$ ).

PSCs: A typical feature at high southern latitudes $\left(-90^{\circ}\right.$ to $-70^{\circ}$ and $-70^{\circ}$ to $-50^{\circ}$ ) is a relatively high positive bias of many MIPAS CTH indices (exceptions are OPER_CI and SVD). Such high clouds above $13 \mathrm{~km}$ in the south are very probably PSCs. Inspecting the corresponding correlation plots shows that only a few lidar samples indicate higher CTHs than MIPAS and most are lower. This might be explained by (a) a smaller sensitivity to optically thin polar stratospheric clouds by the lidar compared to MIPAS and (b) a large inhomogeneity of the PSC field at the end of the polar winter. At that time, due to the preceding denitrification of the stratosphere, PSCs are optically thinner and are not as homogeneous as during the period from June to August.
Argument (a) is also supported by better agreement with the less sensitive MIPAS detection methods OPER_CI and SVD.

Tropical cirrus: Compared to the PSCs, the CTHs of high cirrus clouds in the tropics at an altitude of $11.5-17.5 \mathrm{~km}$ compare better. At these altitudes, in the latitude range $-10^{\circ}-10^{\circ}$ the mean $\mathrm{CTH}$ differences are around $1 \mathrm{~km}$. There are some indications $\left(10^{\circ}-30^{\circ} \mathrm{N} / \mathrm{S}\right)$ of higher detection sensitivities at the upper altitudes, mainly driven by the macro retrieval and less explicitly by SVD and CIOPT_THRESH.

Tropospheric mid-and high-latitude clouds: MIPAS and lidar CTHs of tropospheric clouds at mid and high latitudes at around $6-11 \mathrm{~km}$ agree well, mostly within differences of $1-2 \mathrm{~km}$. This agreement is slightly better for northern than for southern latitudes. The CIOPT_THRESH method and to some extent SVD show some high CTHs $(>15 \mathrm{~km})$ between $30^{\circ} \mathrm{N}$ and $70^{\circ} \mathrm{N}$ that are rather doubtful, but only for a small number of coincidences $(<10)$. As already reported above, this may point to a hypersensitivity of these methods and updates on the altitude thresholds are necessary to improve the methods in future data versions (e.g. Sembhi et al., 2012).

\subsubsection{Conclusions from the SAGE II and GLAS analysis}

The coincidence analysis of the mean difference of CTHs retrieved from MIPAS with respect to the limb occultation instruments SAGE II and the active nadir lidar instrument GLAS shows good agreement for both comparisons, especially for the altitude regions around the tropopause. However, at lower altitudes MIPAS seems to lose sensitivity with respect to SAGE II. This is in contrast to the GLAS comparison where MIPAS shows nearly constant mean differences ( $<2 \mathrm{~km}$, depending on detection method) at the lowest 2-3 altitude levels (troposphere). Increasing positive differences with respect to GLAS for the highest levels (polar stratosphere and UTLS) indicate a hypersensitivity of only 1-2 methods in some latitude regions but may point to slightly higher detection sensitivity than GLAS for ultrathin clouds. This was already postulated in the blind test retrieval results (Sect. 4.3.2).

The nearly parallel orbit geometry displayed by GLAS and MIPAS allows much better coincidence criteria $(2 \mathrm{~h} / 200 \mathrm{~km})$ than for SAGE II $(4 \mathrm{~h} / 400 \mathrm{~km})$. The resulting scanning directions of MIPAS and GLAS through the cloud fields are accordingly very similar in contrast to SAGE II (see also Sect. 5.1.5). The more consistent results for the GLAS coincidences show that a consideration of the limb path smearing of MIPAS, by selecting the maximum CTH of GLAS in the horizontal coincidence window (see above), is crucial and provides a reliable approach to make the nadir and limb CTH measurements comparable. 

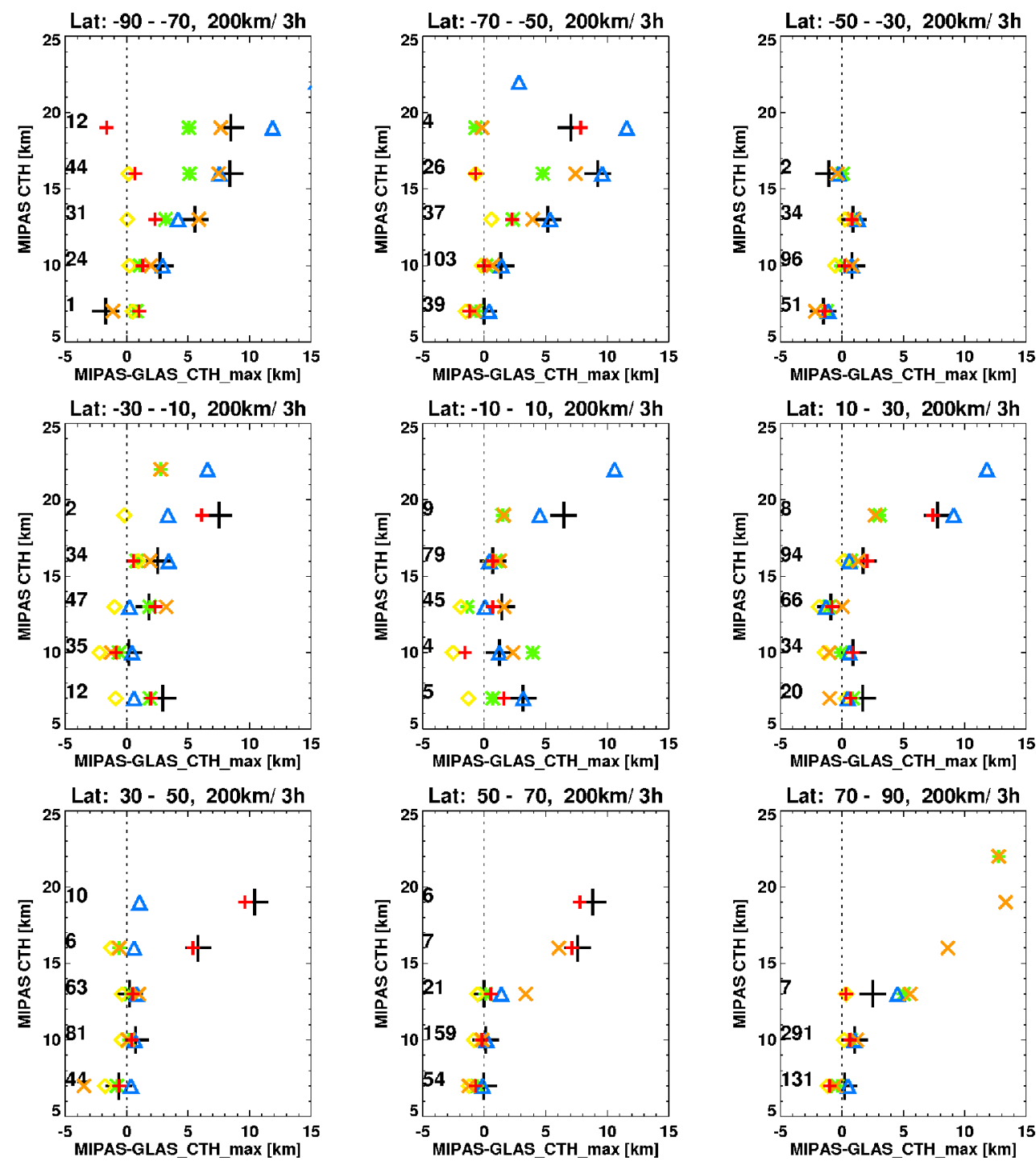

$$
\begin{aligned}
+ & =\text { sum_cloud } \\
* & =\text { ci_thresh } \\
& =\text { oper_ci } \\
x & =\text { ciopt_thresh } \\
\Delta & =\text { macro } \\
+ & =\text { svd }
\end{aligned}
$$

Fig. 18. Altitude-binned differences of cloud top heights between the various MIPAS detection methods and the GLAS lidar co-incidences $(200 \mathrm{~km} / 3 \mathrm{~h})$. Black number represents the number of both-cloudy events for the parameter SUM_CLOUD.

\subsection{GEWEX/ISCCP comparison}

\subsubsection{GEWEX/ISCCP dataset}

The MIPAS cloud products were compared with the datasets prepared for the Global Energy and Water Cycle Experiment (GEWEX) cloud assessment. The GEWEX cloud assessment group (GEWEX, 2010) was initiated by the GEWEX Radiation Panel (GRP) in 2005 to evaluate the reliability of the available global, long-term cloud data products, with a special emphasis on the International Satellite Cloud Climatology Project (ISCCP) (Rossow, et al., 1999).

ISCCP is the best known of cloud climatologies and hence forms the baseline for many cloud comparisons. However, the ISCCP data set is known to be not particularly sensitive to high clouds. Hence, the project has also compared the data to other satellite cloud climatologies, in particular 
to climatologies which make use of the $\mathrm{CO}_{2}$ slicing technique such as AIRS (Aumann et al., 2003). AIRS (Atmospheric Infra Red Sounder) is one of 6 instruments on board the Aqua satellite that was launched in May 2002 and comprises 2378 spectral channels. The fractional cloud cover represents the fraction of clouds in a $45 \times 45 \mathrm{~km}$ area. This product is one of the most sensitive nadir viewing instruments for high level cloud in comparison to other nadir instruments. GEWEX includes the AIRS-LMD retrieval products described by Stubenrauch et al. (2008). Finally, the Along Track Scanning Radiometer (ATSR) cloud product (Poulsen et al., 2011) is used. The ATSR instruments are dual-viewing imaging instruments measuring visible and infrared radiances (at $0.55,0.67,0.87,1.6,3.7,11$ and $12 \mu \mathrm{m}$ ) with $1 \mathrm{~km}$ spatial resolution at the sub-satellite point and operate on different satellite platforms. Data are based on a multi-spectral optimal estimation retrieval of cloud parameters, in particular for ATSR-2 and AATSR. The cloud parameter used in the comparisons with MIPAS is the cloud top pressure.

For statistical comparisons, global datasets of the high cloud amount (HCA), which is defined by the detection of CTHs above a pressure level of $440 \mathrm{hPa}$, were prepared for the different nadir viewing instruments at the resolution of the MIPAS cloud occurrence frequency analysis $\left(20^{\circ}\right.$ longitude $\times 10^{\circ}$ longitude grid).

\subsubsection{Comparisons of high cloud amount}

Figure 19 shows global maps of the high cloud amounts (HCA) for the nadir viewing instruments at the resolution of the MIPAS COF analysis $\left(20^{\circ}\right.$ longitude $\times 10^{\circ}$ longitude grid). The ATSR cloud product shows marginally more sensitivity at mid-latitudes but with lower HCA in some tropical regions than the ISCCP dataset. The AIRS instrument is the most sensitive of the nadir instruments with significantly larger percentages in HCA.

In addition, the ATSR level 2 cloud data set is collocated in time with MIPAS and was used to generate an 'MIPAS-like' product. This new product is more representative of a limbviewing instrument that will assign cloud over a large horizontal footprint. The "MIPAS-like" product was generated by the following steps: (1) Averaging the ATSR orbit information onto a $1^{\circ}$ longitude by $2^{\circ}$ latitude grid. (2) If the high cloud amount (cloud $>440 \mathrm{hPa}$ ) was greater than 0 then the cloud fraction of the grid box was set to one. If a single observation is detected in the larger footprint it is assumed that the MIPAS instrument would have detected it. (3) The data was then projected onto the MIPAS monthly grid. The resulting product was labelled "ATSRMIPAS" and is also shown in Fig. 19 with both the MIPAS cloud occurrence and the difference MIPAS-ATSRMIPAS for March 2004 (three right-hand panels).

Obviously, the limb viewing instrument is more sensitive to thin and high altitude clouds because of the longer path through the atmosphere than that of the nadir instrument. The
HCA for the ATSR "MIPAS-like" product is still less than the MIPAS product, as would be expected due to differences in sensitivity and the limb geometry. However, this product shows strong spatial correlations with the MIPAS product, especially in the tropics. Mid-latitude occurrence frequencies are significantly higher for MIPAS especially over the oceans. In the tropics and high latitudes, differences of up to $40-50 \%$ can be observed.

There are a few regions where the ATSR product shows a larger HCA (e.g. over the north of India, West Siberia, and parts of north Canada). But on a global basis the much smaller HCA for all passive nadir instruments highlights the better detection sensitivity of the limb instrument and the importance of a dataset of cloud parameters from MIPAS to improve global climatologies on cloud occurrences of cirrus clouds.

\subsubsection{A concept on how to compare limb and nadir cloud occurrences}

Usually, in a COF analysis nadir instruments underestimate the true COF due to a lack of sensitivity. Limb based COF analyses will overestimate the amount of clouds seen in the nadir direction due to the limb path smearing effect (Sect. 4.3.1). The ATSR "MIPAS-like" product is a first step to make limb and nadir measurements better comparable.

Similar to the blind test in Sect. 4 where the "true state" ADP is computed from ECMWF data and compared with the retrieved CTH and ADP, it would be better to raytrace the MIPAS limb paths through the horizontally high resolved cloud parameter fields of the nadir instrument and to estimate, for example, an effective limb CTH from the nadir CTHs along the LOS. A similar approach was successfully applied to global nadir BTR composites to create realistic high resolved fields of CTHs (Adams et al., 2009). The study quantified the benefit of limb cloud imaging for infrared limb sounding of tropospheric trace gases.

Additional nadir information on $R_{\text {eff }}$, IWC or vertical IWP would offer the potential to estimate a limb equivalent ADP from the nadir data. Consequentially, the most realistic approach to make cloud occurrence frequencies from nadir and limb measurements comparable would be based on retrieved ADP values for both instrument types, even if the nadir information is only a rough estimate (e.g. as a first approximation any ADP $>0$ is equivalent to a cloud detection in the limb). Detailed analyses and refinements will be necessary to test and quantify the benefit of the new concept. However, the results of the blind tests in Sect. 4 already show that the concept should be applied for comparisons of limb measurements and 3-D model data with incorporated cloud physics. 
ATSR 200403 hca

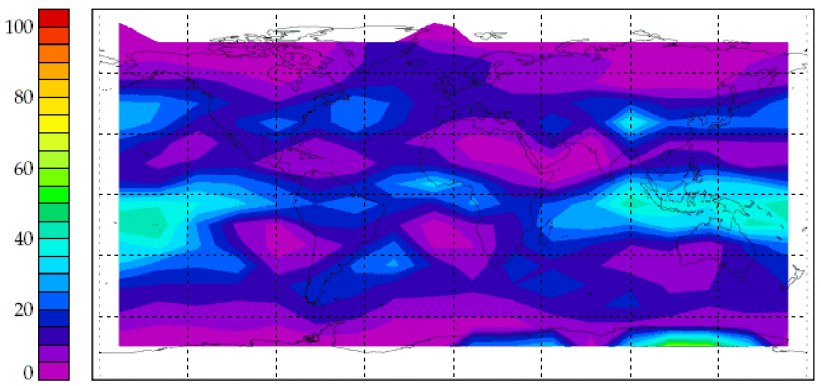

ISCCP 200403 hca

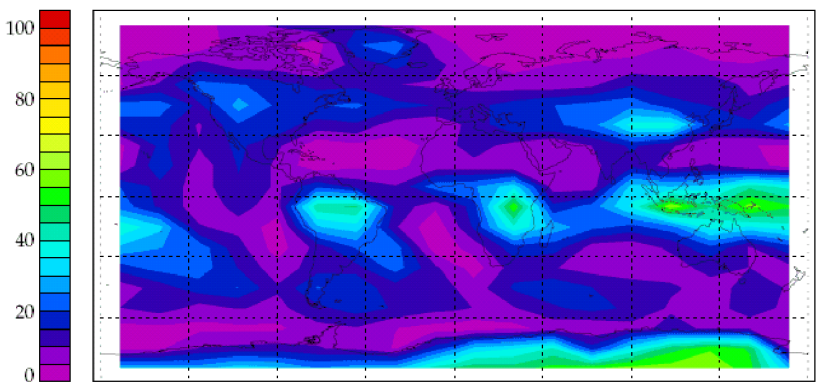

AIRS 200403 hca

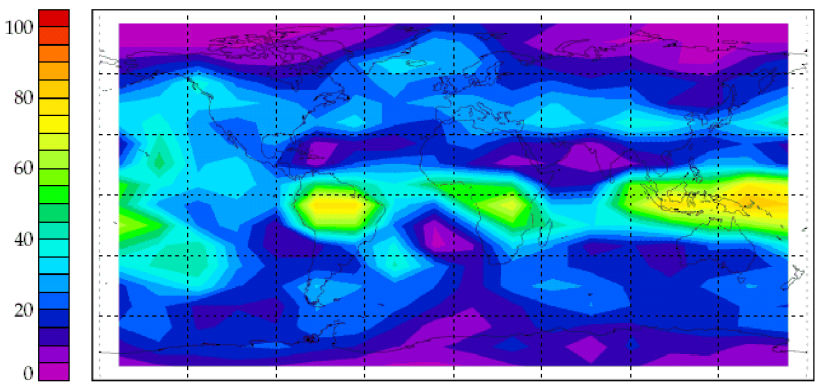

ATSRMIPAS 200403 hca
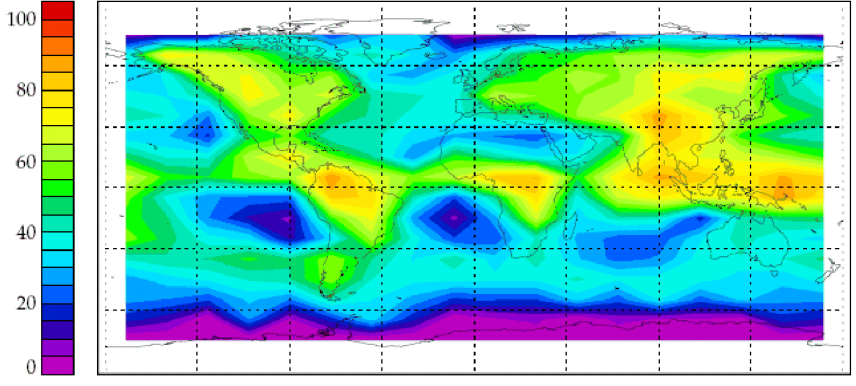

MIPAS_SUM_CLOUD 200403 hca

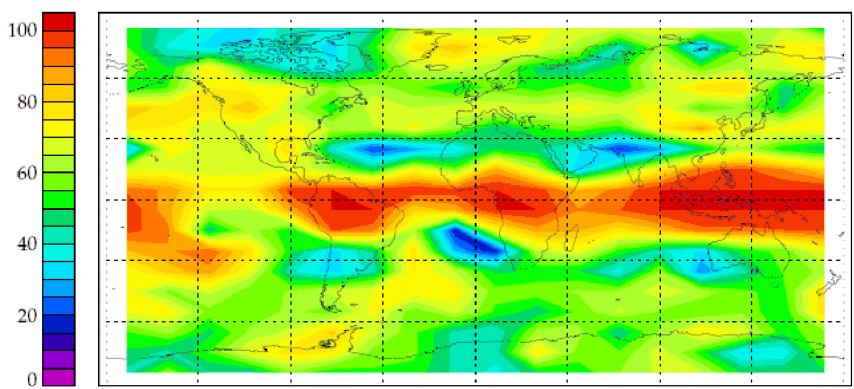

difference MIPAS_SUM_CLOUD $200403 \mathrm{hca}$
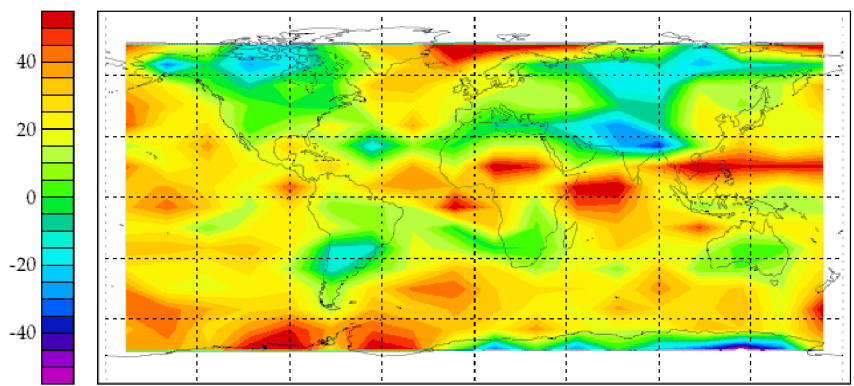

Fig. 19. Comparison of ATSR, ISCCP, AIRS (left column), as well as the MIPAS-like ATSR product (details see text), MIPAS COF of the summary information SUM_CLOUD, and the difference between MIPAS and MIPAS-like ATSR (right column) for high cloud amounts (hca: $p<440 \mathrm{hPa}$ ) for March 2004 .

\section{Conclusions and outlook}

A new cloud parameter processor for MIPAS with near-realtime capability has been developed. Various cloud detection and classification methods as well as micro- and macrophysical parameter retrievals were implemented in the processor. The validation of cloud parameters shows in many cases a good correspondence with selected validation instruments and datasets. However, differences are also observed but indicating different detection sensitivity between the detection methods and instruments for varying regions of the UTLS and mid troposphere. Some retrieved parameters, such as the newly deduced area density path (ADP), and the classification polar stratospheric clouds (PSC) types (not presented in detail), show the capability for new innovative research objectives, such as the understanding of cloud formation processes and the spatial and temporal distribution of optically thin cirrus and polar stratospheric clouds.
Various validation techniques were applied. The analyses show that it is often difficult to compare parameters deduced by complementary measurement techniques (e.g. nadir and limb). Validation comparisons need to consider differences in sensitivity, viewing geometries, FOV or the vertical and horizontal sampling of the two sensors of interest, otherwise results may be misleading. A blind-test retrieval (BTR) approach was developed to address this problem. BTR results based on modelled spectra of limb sequences for various cloudy scenes show the high sensitivity in cloud detection for various MIPAS methods. The combination of the different techniques to deduce one $\mathrm{CTH}$ parameter and the definition of a cloud confidence flag are a new approach for a more reliable detection of clouds by IR limb sounders. This has not yet been applied in an optimised form to the MIPAS data. However, the validation results of the current processor version of cloud occurrences and CTH via coincidence and 
the geographical statistical means with various sensors are quite consistent and satisfactory.

For example, the overall detection sensitivity of the processor is similar to, or in some regions even better than, the lidar in the GLAS space instrument, and also similar to ground-based lidars (not shown, Höpfner et al., 2006a; Spang et al., 2010b). The MIPAS results for the occurrence frequencies of high amounts of cloud $(<440 \mathrm{hPa})$ show significantly higher values on global scales compared to passive nadir viewers in the GEWEX dataset or ISCCP as part of GEWEX, even if the limb-smearing effect is taken into account in the nadir analysis.

The BTR results give evidence of a quantitatively defined detection threshold for subvisible cirrus clouds (SVC) in

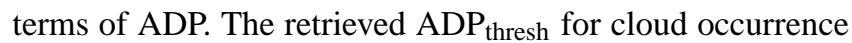
of $10^{7} \mu^{2} \mathrm{~cm}^{-2}$ is independent of unknowns about cloud inhomogeneities along the line of sight (LOS) and is a representative quantity under various conditions (different altitudes and geographical regions). Depending on the horizontal extent of the cloud along the LOS, for example, a typically expanded cirrus structure of $300 \mathrm{~km}$ and a very narrow cloud of $3 \mathrm{~km}$, an ice water content IWC threshold of $\sim 10^{-7} \mathrm{~g} \mathrm{~m}^{-3}$ and $\sim 10^{-5} \mathrm{~g} \mathrm{~m}^{-3}$, respectively, is estimated. The larger IWC threshold value represents SVCs of extremely low optical thickness. Based on airborne measurements during the Tropical Composition, Cloud and Climate Coupling (TC4) campaign in comparison to the CALIOP lidar on the CALIPSO satellite, Davis et al. (2011) postulated that the space lidar might miss $\sim 2 / 3$ of these optically thin clouds $(\tau<0.01)$. Consequently, a comparison of CALIPSO and MIPAS, as already performed for PSCs in Höpfner et al. (2009) is highly recommended for future analyses to prove the indirect conclusion that MIPAS might be able to detect optically thinner cirrus clouds more effectively than CALIPSO.

The processing of the full MIPAS time series $(\sim 10 \mathrm{yr})$ would create a unique and complementary data series of cloud parameters (e.g. compared to products of nadir viewers) for climate related studies with respect to cloud processes. Comparisons with models incorporating cloud physics - such as the ECMWF, chemical transport and climate models - are a major issue for future applications. The MIPclouds data can be used to validate the model capabilities to predict the cirrus distribution and coverage as well as water transport in the UTLS region. However, it is necessary to apply a kind of MIPAS simulator to the model data to properly consider the FOV, sampling, sensitivity issues and the limb path integration. In the future, new topics will come within the scope of a possible extension of the MIPclouds processor, for example: further improvements and developments are desirable for the classification of various particle types in the troposphere and lower stratosphere such as the differentiation of various aerosol types (e.g. volcanic ash) from liquid and ice water clouds.

\section{Appendix A}

$\begin{array}{ll}\text { Abbreviations and acronyms } \\ \text { ADP } & \text { Surface area density path } \\ \text { A } & \text { Surface area density } \\ \text { BTD } & \text { Brightness temperature difference } \\ \text { BTR } & \text { Blind test retrieval } \\ \text { CEX } & \text { Cloud extinction } \\ \text { CI } & \text { Cloud index } \\ \text { CIOPT_THRESH } & \text { Optimised CI threshold method with } \\ & \text { latitude and altitude dependency } \\ \text { CI_THRESH } & \text { CI threshold method based on CI cli- } \\ & \text { matology for 2003 } \\ \text { COF } & \text { Cloud occurrence frequency } \\ \text { CTH } & \text { Cloud top height } \\ \text { CTT } & \text { Cloud top temperature } \\ \text { CSDB } & \text { Cloud scenario database } \\ \text { FOV } & \text { Field of view } \\ \text { GI } & \text { Gas index } \\ \text { IWC } & \text { Ice water content } \\ \text { IWP } & \text { Ice water path } \\ \text { LOS } & \text { Line of sight } \\ \text { LWP } & \text { Liquid water path } \\ \text { MIPclouds } & \text { MIPAS clouds parameter processor } \\ \text { MW } & \text { Microwindow } \\ \text { NAT } & \text { Nitric acid trihydrate } \\ \text { OPER_CI } & \text { ESA operational 12 processing CI } \\ & \text { method } \\ \text { PSC } & \text { Polar stratospheric cloud } \\ R_{\text {eff }} & \text { Effective radius of the particle size } \\ & \text { distribution } \\ \text { STS } & \text { Supercooled ternary solutions } \\ \text { SUM_CLOUD } & \text { Summary cloud information param- } \\ & \text { eter on CTH, CTT, etc. } \\ \text { SVD } & \text { Single value decomposition (detec- } \\ & \text { tion method) } \\ \text { SVC } & \text { Subvisible cirrus cloud } \\ \text { VDP } & \text { Volume density path } \\ & \end{array}$

\section{Supplementary material related to this article is available online at: http://www.atmos-chem-phys.net/12/ 7135/2012/acp-12-7135-2012-supplement.pdf.}

Acknowledgements. The authors gratefully acknowledge S. P. Palm (Science Systems and Applications Inc., Lanham, Maryland, USA) and J.D. Spinhirne (NASA, Goddard Space Flight Centre) for providing GLAS data as well as P. H. Wang (Science and Technology Corporation) for preparing and providing the SAGE II V6 data. The Oxford authors acknowledge support from the UK National Centre for Earth Observation. R. Spang would like to thank S. Rohs (Forschungszentrum Jülich) for support in the 
validation activities of SAGE II, and R. Müller (Forschungszentrum Jülich) for discussions on the scientific objectives of the manuscript. Part of this work was supported by ESA through the MIPclouds project: "Cloud Information Retrieval from MIPAS Measurements”, AO/1-5255/06/I-OL.

The service charges for this open access publication have been covered by a Research Centre of the Helmholtz Association.

Edited by: P. Spichtinger

\section{References}

Adams, S., Spang, R., Preusse, P., and Heinemann, G.: The benefit of limb cloud imaging for infrared limb sounding of tropospheric trace gases, Atmos. Meas. Tech., 2, 287-298, doi:10.5194/amt2-287-2009, 2009.

Aumann, H. H., Chahine, M. T., Gautier, C., Goldberg, M. D., Kalnay, E., McMillin, L. M., Revercomb, H., Rosenkranz, P. W., Smith, W. L., Staelin, D. H., Strow, L. L., and Susskind, J.: AIRS/AMSU/HSB on the Aqua mission: design, science objectives, data products, and processing systems, IEEE Trans. Geosci. Remote Sens., 41, 253-264, 2003.

Baran, A. J., Francis, P. N., Labonnote, L.-C., and DoutriauxBoucher, M.: A scattering phase function for ice cloud: Tests of applicability using aircraft and satellite multi-angle multi wavelength radiance measurements of cirrus, Q. J. Roy . Meteorol. Soc., 127, 2395-2416, 2001.

Davis, S., Hlavka, D., Jensen, E., Rosenlof, K., Yang, Q., Schmidt, S., Borrmann, S., Frey, W., Lawson, P., Voemel, H., and Bui, T. P.: In situ and lidar observations of subvisible cirrus clouds during TC4, J. Geophys. Res., 115, D00J17, doi:10.1029/2009JD013093, 2010.

Drdla, K. and Müller, R.: Temperature thresholds for polar stratospheric ozone loss, Atmos. Chem. Phys. Discuss., 10, $28687-$ 28720, doi:10.5194/acpd-10-28687-2010, 2010.

Dudhia, A., Morris, P. E., and Wells, R. J.: Fast monochromatic radiative transfer calculations for limb sounding, J. Quant. Spectrosc. Rad. Trans., 74, 745-756, 2002.

ESA: Candidate Earth Explorer Core Missions - Report for Assessment: PREMIER - PRocess Exploitation through Measurements of Infrared and millimetre-wave Emitted Radiation, SP-1313/5, ESA Publications Division, ESTEC, Keplerlaan 1, 2200 AG Noordwijk, The Netherlands, 2008.

Evans, K. F., Walter, S. J., Heymsfield, A. J., and Deeter, M. N.: Modeling of submillimeter passive remote sensing of cirrus clouds, J. Appl. Meteorol., 37, 184-205, 1998a.

Evans, K. F.: The spherical harmonics discrete ordinate method for three-dimensional atmospheric radiative transfer, J. Atmos. Sci., 55, 429-446, 1998b.

Ewen, G. B. L., Grainger, R. G., Lambert, A., and Baran, A. J.: Infrared radiative transfer modelling in a $3 \mathrm{D}$ scattering cloudy atmosphere: Application to limb sounding measurements of cirrus, J. Quant. Spectrosc. Rad. Trans., 96, 45-74, 2005.

Eyring, V., Butchart, N., Waugh, D. W., Akiyoshi, H., Austin, J., Bekki, S., Bodeker, G. E., Boville, B. A., Bruhl, C., Chipperfield, M. P., Cordero, E., Dameris, M., Deushi, M., Fioletov, V. E., Frith, S. M., Garcia, R. R., Gettelman, A., Giorgetta,
M. A., Grewe, V., Jourdain, L., Kinnison, D. E., Mancini, E., Manzini, E., Marchand, M., Marsh, D. R., Nagashima, T., Newman, P. A., Nielsen, J. E., Pawson, S., Pitari, G., Plummer, D. A., Rozanov, E., Schraner, M., Shepherd, T. G., Shibata, K., Stolarski, R. S., Struthers, H., Tian, W., and Yoshiki, M.: Assessment of temperature, trace species and ozone in chemistry-climate simulations of the recent past, J. Geophys. Res. 111, D22308, doi:10.1029/2006JD007327, 2006.

Fischer, H., Birk, M., Blom, C., Carli, B., Carlotti, M., von Clarmann, T., Delbouille, L., Dudhia, A., Ehhalt, D., Endemann, M., Flaud, J. M., Gessner, R., Kleinert, A., Koopman, R., Langen, J., López-Puertas, M., Mosner, P., Nett, H., Oelhaf, H., Perron, G., Remedios, J., Rudolfi, M., Stiller, G., and Zander, R.: MIPAS: an instrument for atmospheric and climate research, Atmos. Chem. Phys., 8, 2151-2188, doi:10.5194/acp-8-2151-2008, 2008.

GEWEX, GEWEX cloud assessment, http://climserv.ipsl. Polytechnique.fr/gewexca/presentation.html, last access: November, 2010.

Greenhough, J., Remedios, J. J., Sembhi, H., and Kramer, L. J.: Towards cloud detection and cloud frequency distributions from MIPAS infra-red observations, Adv. Space Res., 36, 800-806, 2005.

Hanson, R., Stutz, J., and Cheeseman, P.: Bayesian Classification Theory, NASA, Technical Report FIA-90-12-7-01, May, 1991.

Höpfner, M.: Study on the impact of polar stratospheric clouds on high resolution mid-IR limb emission spectra, J. Quant. Spectrosc. Radiat. Transfer, 83, 1, 93-107, 2004.

Höpfner, M., Luo, B. P., Massoli, P., Cairo, F., Spang, R., Snels, M., Donfrancesco, G. D., Stiller, G., von Clarmann, T., Fischer, H., and Biermann, U.: Spectroscopic evidence for NAT, STS, and ice in MIPAS infrared limb emission measurements of polar stratospheric clouds, Atmos. Chem. Phys., 6, 1201-1219, doi:10.5194/acp-6-1201-2006, 2006a.

Höpfner, M., Larsen, N., Spang, R., Luo, B. P., Ma, J., Svendsen, S. H., Eckermann, S. D., Knudsen, B., Massoli, P., Cairo, F., Stiller, G., v. Clarmann, T., and Fischer, H.: MIPAS detects Antarctic stratospheric belt of NAT PSCs caused by mountain waves, Atmos. Chem. Phys., 6, 1221-1230, doi:10.5194/acp-6-1221-2006, 2006b.

Höpfner, M., Pitts, M. C., and Poole, L. R., Comparison between CALIPSO and MIPAS observations of polar stratospheric clouds, J. Geophys. Res., 114, D00H05, doi:10.1029/2009JD012114, 2009.

Hoffmann, L., Kaufmann, M., Spang, R., Müller, R., Remedios, J. J., Moore, D. P., Volk, C. M., von Clarmann, T., and Riese, M.: Envisat MIPAS measurements of CFC-11: retrieval, validation, and climatology, Atmos. Chem. Phys., 8, 3671-3688, doi:10.5194/acp-8-3671-2008, 2008.

Hurley, J., Dudhia, A., and Grainger, R. G.: Cloud detection for MIPAS using singular vector decomposition, Atmos. Meas. Tech., 2, 533-547, doi:10.5194/amt-2-533-2009, 2009.

Hurley, J., Dudhia, A., and Grainger, R. G.: Retrieval of macrophysical cloud parameters from MIPAS: algorithm description, Atmos. Meas. Tech., 4, 683-704, doi:10.5194/amt-4-683-2011, 2011.

Kärcher B. and Spichtinger, P.: Cloud-controlling Factors of Cirrus, in: Clouds in the Perturbed Climate System: Their Relationship for Energy Balance, Atmospheric Dynamics and Precipitation, in the Strüngmann Forum Report, edited by: Heintzenberg, J. and 
Charlson, R. J., MIT Press, 235-267, 2009.

Kerridge, B. J., Siddans, R., Reburn, J., Jay, V., Latter, B., Lama, F., Dudhia, A., Grainger, D., Burgess, A., Höpfner, M., Steck, T., Emde, C., Eriksson, P., Ekstrom, M., and Baran, A.: Consideration of mission studying chemistry of the UTLS - Final Report, ESA Contract No 15457/01/NL/MM, 2004.

Kiefer, M., von Clarmann, T., Grabowski, U., De Laurentis, M., Mantovani, R., Milz, M., and Ridolfi, M.: Characterization of MIPAS elevation pointing, Atmos. Chem. Phys., 7, 1615-1628, doi:10.5194/acp-7-1615-2007, 2007.

Lawson, R. P., Pilson, B., Baker, B., Mo, Q., Jensen, E., Pfister, L., and Bui, P.: Aircraft measurements of microphysical properties of subvisible cirrus in the tropical tropopause layer, Atmos. Chem. Phys., 8, 16090-1620, doi:10.5194/acp-8-16092008, 2008.

Liao, X., Rind, D., and Rossow, W. B.: Comparison between SAGE II and ISCCP high-level clouds, Part I: Global and zonal mean cloud amounts, J. Geophys. Res., 100, 1121-1135, 1995.

Luo, B. P., Peter, T., Fueglistaler, S., Wernli, H.,Wirth, M., Kiemle, C., Flentje, H., Yushkov, V. A., Khattatov, V., Rudakov, V., Thomas, A., Borrmann, S., Toci, G., Mazzinghi, P., Beuermann, J., Schiller, C., Cairo, F., Di Donfrancesco, G., Adriani, A., Volk, C. M., Strom, J., Noone, K., Mitev, V., MacKenzie, R. A., Carslaw, K. S., Trautmann, T., Santacesaria, V., and Stefanutti, L.: Dehydration potential of ultrathin clouds at the tropical tropopause, Geophys. Res. Lett., 30, 1557, doi:10.1029/2002GL016737, 2003.

McFarquhar, G. M. and Heymsfield, A. J., Spinhirne, J., and Hart, B.: Thin and Subvisual Tropopause Tropical Cirrus: Observations and Radiative Impacts. J. Atmos. Sci., 57, 1841-1853, 2000.

Massie, S., Gille, J., Khosravi, R., Lee, H., Kinnison, D., Francis, G., Nardi, B., Eden, T., Craig, C., Halvorson, C., Coffey, M., Packman, D., Cavanaugh, C., Craft, J., Dean, V., Ellis, D., Barnett, J., Hepplewhite, C., Lambert, A., Manney, G., Strawa, A., and Legg, M.: High Resolution Dynamics Limb Sounder observations of polar stratospheric clouds and subvisible cirrus, J. Geophys. Res., 112, D24S31, doi:10.1029/2007JD008788, 2007.

McCormick, M. P.: SAGE II: An overview, Adv. Space Res., 7, 319-326, 1987.

Mergenthaler, J., Roche, A., Kumer, J., and Ely, G.: Cryogenic Limb Array Etalon Spectrometer observations of tropical cirrus, J. Geophys. Res., 104, 22183-22194, 1999.

Milz, M., von Clarmann, T., Fischer, H., Glatthor, N., Grabowski, U., Höpfner, M., Kellmann, S., Kiefer, M., Linden, A., Mengistu Tsidu, G., Steck, T., Stiller, G. P., Funke, B., López-Puertas, M., and Koukouli, M.: Water vapor distributions measured with the Michelson Interferometer for Passive Atmospheric Sounding on board Envisat (MIPAS/Envisat), J. Geophys. Res., 110, D24307, doi:10.1029/2005JD005973, 2005.

Peter, Th., Luo, B. P., Wirth, M., Kiemle, C., Flentje, H., Yushkov, V. A., Khattatov, V., Rudakov, V., Thomas, A., Borrmann, S., Toci, G., Mazzinghi, P., Beuermann, J., Schiller, C., Cairo, F., Di Donfrancesco, G., Adriani, A., Volk, C. M., Strom, J., Noone, K., Mitev, V., MacKenzie, R. A., Carslaw, K. S., Trautmann, T., Santacesaria, V., and Stefanutti, L.: Ultrathin Tropical Tropopause Clouds (UTTCs): I. Cloud morphology and occurrence, Atmos. Chem. Phys., 3, 1083-1091, doi:10.5194/acp-3-1083-2003, 2003.
Poulsen, C. A., Watts, P. D., Thomas, G. E., Sayer, A. M., Siddans, R., Grainger, R. G., Lawrence, B. N., Campmany, E., Dean, S. M., and Arnold, C.: Cloud retrievals from satellite data using optimal estimation: evaluation and application to ATSR, Atmos. Meas. Tech. Discuss., 4, 2389-2431, doi:10.5194/amtd-4-23892011, 2011.

Raspollini, P, Carli, B., Carlotti, M., Ceccherini, S., Dinelli, B. M., Dudhia, A., Flaude, J.-M., Hoepfner, M., Jay, V., Magnani, L., Oelhaf, H., Piccolo, C., Prosperi, M., Remedios, J. J., Ridolfi, M., and Spang, R.: SPIE Proc., Level 2 near-real-time analysis of MIPAS measurements on ENVISAT, Remote Sensing of Clouds and the Atmosphere VII, 4882, Agia Pelagia, Crete, Greece, 2002.

Raspollini, P., Belotti, C., Burgess, A., Carli, B., Carlotti, M., Ceccherini, S., Dinelli, B. M., Dudhia, A., Flaud, J.-M., Funke, B., Höpfner, M., López-Puertas, M., Payne, V., Piccolo, C., Remedios, J. J., Ridolfi, M., and Spang, R.: MIPAS level 2 operational analysis, Atmos. Chem. Phys., 6, 5605-5630, doi:10.5194/acp6-5605-2006, 2006.

Remedios J.J., Spang, R., Detection of cloud effects in MIPAS spectral data and implications for the MIPAS operational processor, Proceedings of the ENVISAT Calibration Review, 9-13 September 2002, ESA-ESTEC, Noordwijk, The Netherlands, 2002.

Remedios, J. J., Leigh, R. J., Waterfall, A. M., Moore, D. P., Sembhi, H., Parkes, I., Greenhough, J., Chipperfield, M. P., and Hauglustaine, D.: MIPAS reference atmospheres and comparisons to V4.61/V4.62 MIPAS level 2 geophysical data sets, Atmos. Chem. Phys. Discuss., 7, 9973-10017, doi:10.5194/acpd-79973-2007, 2007.

Ridolfi, M., Carli, B., Carlotti, M., von Clarmann, Thomas, Dinelli, B. M., Dudhia, A., Flaud, J.-M., Höpfner, M., Morris, P. E., Raspollini, P., Stiller, G., and Wells, R. J.: Optimized Forward and Retrieval Scheme for MIPAS Near-Real-Time Data Processing, Appl. Opt. 39, 1323-1340, 2000.

Riese, M., Preusse, P., Spang, R., Ern, M., Jarisch, M., Grossmann, K. U., Offermann, D.: Measurements of trace gases by the Cryogenic Infrared Spectrometers and Telscopes for the Atmosphere (CRISTA) experiment, Adv. Space Res., 19, 563-566, 1997.

Riese, M., Spang, R., Preusse, P., Ern, M., Jarisch, M., Offermann, D., and Grossmann, K. U.: Cryogenic Infrared Spectrometers and Telescopes for the Atmosphere (CRISTA) data Processing and atmospheric temperature and trace gas retrieval, J. Geophys. Res., 104, 16349-16367, 1999.

Riese, M., Friedl-Vallon, F., Spang, R., Preuße, P., Schiller, C., Hoffmann, L., Oelhaf, H., von Clarmann, Th., andHöpfner, M.: Global Limb Radiance Imager for the Atmosphere (GLORIA): Scientific Objectives, Adv. Space Res., 36, 989-995, 2005.

Rossow, W. B. and Schiffer, R. A.: Advances in understanding clouds from ISCCP, B. Am. Meteorol. Soc., 80, 2261-2287, 1999.

SAGE, SAGE II information on data products at: http: //www-sage2.larc.nasa.gov/Version6-2Data.html, last access: April, 2011.

Solomon, S.: Stratospheric ozone depletion: A review of concepts and history, Rev. Geophys., 37, 275-316, doi:10.1029/1999RG900008, 1999.

Sassen, K., and Cho, B. S.: Subvisual-thin cirrus clouds lidar data set for satellite verification and climatological research, J. Appl. Meteorol., 31, 1275-1285, 1992. 
Sassen, K., Griffin, M. K., and Dodd, G. C.: Optical scattering and microphysical properties of subvisible cirrus clouds, and climatic implications, J. Appl. Meteorol., 28, 91-98, 1989.

Sembhi, H., Remedios, J., Trent, T., Moore, D. P., Spang, R., Massie, S., and Vernier, J.-P.: MIPAS detection of cloud and aerosol particle occurrence in the UTLS with comparison to HIRDLS and CALIOP, Atmos. Meas. Tech. Discuss., 5, 17951841, doi:10.5194/amtd-5-1795-2012, 2012.

Spang, R., Riese, M., Eidmann, G., Offermann, D., Pfister, L., and Wang, P. H.: CRISTA observations of cirrus clouds around the tropopause, J. Geophys. Res., 107, 8174, doi:0/1029/2002JD000698, 2002.

Spang R. and Remedios, J., Observations of a distinctive infrared spectral feature in the atmospheric spectra of polar stratospheric clouds measured by the CRISTA instrument, Geophys. Res. Lett., 30, 1875, doi:10.1029/2003GL017231, 2003.

Spang, R., Remedios, J. J., and Barkley, M., Colour Indices for the Detection and Differentiation of Cloud Types in Infra-red Limb Emission Spectra, Adv. Space Res., 33, pp.1041-1047, 2004.

Spang, R., Remedios, J. J., Kramer, L. J., Poole, L. R., Fromm, M. D., Müller, M., Baumgarten, G., and Konopka, P.: Polar stratospheric cloud observations by MIPAS on ENVISAT: detection method, validation and analysis of the northern hemisphere winter 2002/2003, Atmos. Chem. Phys., 5, 679-692, doi:10.5194/acp-5-679-2005, 2005a.

Spang, R., Remedios, J. J., Tilmes, S., and Riese, M.: MIPAS observation of polar stratospheric clouds in the Arctic 2002/2003 and Antarctic 2003 winters, Adv. Space Res., 36, 868-878, 2005b.

Spang, R., Griessbach, S., Höpfner, M., Dudhia, A., Hurley, J., Siddans, R., Waterfall, A., Remedios, J. J., and Sembhi., H.: Technical Note: Retrievability of MIPAS cloud parameter, ESA-ESRIN Contract No. 20601/07/I-OL, March 2008.

Spang, R., Arndt, K., Dudhia, A., Grießbach, S., Höpfner, M., Hurley, J., Remedios, J. J., Sembhi, H., and Siddans, R.: Algorithm Technical Basis Document: Cloud Information Retrieval from MIPAS measurements, ESA-ESRIN Contract No. 20601/07/IOL, Version 2.1, 10 June, 2010a.

Spang, R., Höpfner, M., Dudhia, A., Siddans, R., Waterfall, A., Poulsen, C., Remedios, J. J., and Sembhi, H.: Product Validation Report for the MIPAS cloud parameter processor, ESA-ESRIN Contract No. 20601/07/I-OL, Version: 10 June, 2010b.
Spinhirne, J. D., Palm, S. P., Hart, W. D., Hlavka, D. L., and Welton, E. J.: Cloud and aerosol measurements from GLAS: Overview and initial results, Geophys, Res. Lett., 32, L22S03, doi:10.1029/2005GL023507, 2005.

Stiller, G. P. (Editor), The Karlsruhe Optimized and Precise Radiative transfer Algorithm (KOPRA), Forschungszentrum Karlsruhe, Wissenschaftliche Berichte, Bericht Nr. 6487, 'http:// www.imk-asf.kit.edu/english/312.php, last access: 21 July 2012, 2000.

Stubenrauch, C. J., Cros, S., Lamquin, N., Armante, R., Ch'edin, A., Crevoisier, C., and Scott, N. A.: Cloud properties from AIRS and evaluation with CALIPSO, J. Geophys. Res., 113, D00A10, doi:10.1029/2008JD009928, 2008.

Stubenrauch, C. J., Cros, S., Guignard, A., and Lamquin, N.: A 6-year global cloud climatology from the Atmospheric Infra Red Sounder AIRS and a statistical analysis in synergy with CALIPSO and CloudSat, Atmos. Chem. Phys., 10, 7197-7214, doi:10.5194/acp-10-7197-2010, 2010.

von Clarmann, T., Glatthor, N., Grabowski, U., H“” opfner, M., Kellmann, S., Kiefer, M., Linden, A., Mengistu Tsidu, G., Milz, M., Steck, T., Stiller, G. P., Wang, D. Y., Fischer, H., Funke, B., Gil-Lopez, S., and Lopez-Puertas, M.: Retrieval of temperature and tangent altitude pointing from limb emission spectra recorded from space by the Michelson Interferometer for Passive Atmospheric Sounding (MIPAS), J. Geophys. Res., 108, 4736, doi:10.1029/2003JD003602, 2003.

Wang, P. H., Minnis, P., McCormick, M. P., Kent, G. S., and Skeens, K. S.: A 6-year climatology of cloud occurrence frequency from SAGE II observations (1985-1990), J. Geophys. Res., 101, 29407-29429, 1996.

Wang, P.-H., Veiga, R. E., Vann, L. B., Minnis, P., and Kent, G. S.: A further study of the method for estimation of SAGE II opaque cloud occurrence, J. Geophys. Res., 106, 12603-12613, doi:10.1029/2001JD900138, 2001.

Zhang, M. H., Lin, W. Y. Klein, S. A., Bacmeister, J. T., Bony, S, Cederwall, R. T., Del Genio,A., D. , Hack, J. J., Loeb, N. G., Lohmann, U., Minnis, P, Musat, I., Pincus, R., Stier, P., Suarez,M. J., Webb, M. J., Wu, J. B., Xie, S. C., Yao, M.-S., and Zhang, J. H.: Comparing clouds and their seasonal variations in 10 atmospheric general circulation models with satellite measurements, J. Geophys. Res. 110, D15S02, doi:10.1029/2004JD005021, 2005. 